\title{
Effect of corticosteroid therapy on bromsulphthalein excretion in active chronic hepatitis
}

\author{
G. C. COOK, 1 MARTA VELASCO, ${ }^{2}$ AND SHEILA SHERLOCK \\ From the Department of Medicine, The Royal Free Hospital, London
}

The aetiology of active chronic hepatitis or lupoid hepatitis (Saint, King, Joske, and Finckh, 1953; Bearn, Kunkel, and Slater, 1956; Mackay, Taft, and Cowling, 1956; Bartholomew, Cain, Baggenstoss, and Hagedorn, 1960; Read, Sherlock, and Harrison, 1963; MacLachlan, Rodnan, Cooper, and Fennell, 1965 ) is not completely understood. It is a stage in a continuous process beginning with an acute hepatic insult, which may sometimes be virus hepatitis, and ending in post-necrotic cirrhosis (Bartholomew, Hagedorn, Cain, and Baggenstoss, 1958; Page and Good, 1960; Jones and Castleman, 1962). The place of corticosteroids in both short- and long-term treatment is undecided. The present report concerns bromsulphthalein (BSP) excretion and metabolism in patients in a controlled trial of this treatment which is currently in progress at the Royal Free Hospital. Additional studies in other patients with active chronic hepatitis who were not in the trial, and in patients with cholestatic virus hepatitis and extrahepatic obstructive jaundice are also reported.

\section{PATIENTS}

In all patients the diagnosis was confirmed by serum biochemistry and hepatic histology obtained by aspiration biopsy specimens (Read et al., 1963).

Twenty-two patients with active chronic hepatitis who had not previously received corticosteroids or ACTH had bromsulphthalein (BSP) disappearance curves determined. They were in the controlled trial, and were divided into two random groups by a blind technique using sealed envelopes. One group received $15 \mathrm{mg}$ prednisolone daily indefinitely; the second was not treated with corticosteroids. Other treatment, $i e$, diuretics, and supportive measures, was similar in each group. Tables I and II give the sex, age, and initial BSP and biochemical indices in the 22 patients in the two groups. The mean time between inclusion to the trial and the last BSP estimation was 32 and 28 weeks in the two groups respectively.

In an attempt to elucidate the mechanism of the alter-

${ }^{1}$ Correspondence:" Dr G. C. Cook, Department of Medicine, The Royal Free Hospital, London, W.C.1.

'Present Address: Hospital del Salvador, Casilla 70-D, Santiago, Chile. ation in BSP retention produced in the patients in the controlled trial by corticosteroids, BSP storage (S), and transport maximum (Tm) estimations were done in two further groups of patients with active chronic hepatitis. Twenty-four patients with active chronic hepatitis had a single BSP storage (S) and transport maximum (Tm) determination; they included patients $1,2,4$, and 12 in the controlled trial (Table III). Fourteen of them were receiving 10 to $30 \mathrm{mg}$ prednisolone daily; 10 were not having corticosteroids. In 29 other patients with active chronic hepatitis who were not all in the therapeutic trial, and were not therefore strictly randomly selected, serial BSP storage (S) and transport maximum (Tm) estimations were made; they included patients $7,8,9,10,15,17,19$, 20,21 , and 22 , who were studied in the controlled trial. Sixteen had received corticosteroids or ACTH in the past, but not for at least 12 months. In 16, estimations were performed before and after starting $15 \mathrm{mg}$ prednisolone daily (Table IV); the other 13 acted as controls (Table V).

Storage (S) and transport maximum (Tm) for BSP were estimated in a further four patients - three with cholestatic virus hepatitis and one with extrahepatic obstructive jaundice-in order to obtain additional information about the mechanism of the alteration in BSP excretion during corticosteroid treatment (Table VI). Three of them were given $30 \mathrm{mg}$ prednisolone daily.

In 21 of the patients with active chronic hepatitis, nine of whom were in the controlled trial (nos. 7, $89,10,17$, $19,20,21$, and 22), plasma samples during BSP disappearance curves were subjected to chromatographic analysis of BSP. Twelve had estimations before and after starting $15 \mathrm{mg}$ prednisolone daily; nine acted as controls (Tables VII and VIII).

\section{METHODS}

Bromsulphthalein (BSP) disappearance curves were performed after an overnight fast following the intravenous injection of $5.0 \mathrm{mg}$ BSP per $\mathrm{kg}$ body weight. Venous blood was taken from the opposite arm at three, eight, 12, 20,30 , and 45 minutes after injection of BSP. Plasma BSP was estimated on the same day by a method based on that of Seligson, Marino, and Dodson (1957). To $3.5 \mathrm{ml}$ alkaline buffer $(p \mathrm{H} \quad 10.6) \quad\left(12.2 \quad \mathrm{~g} \mathrm{Na} \quad \mathrm{NPO}_{4} .7_{2} \mathrm{O}\right.$, $1.77 \mathrm{~g} \mathrm{Na}_{3} \mathrm{PO}_{4} \mathrm{H}_{2} \mathrm{O}$, and $3.20 \mathrm{~g}$ of sodium $p$-toluene sulphonate, made up to $500 \mathrm{ml}$ with distilled water), $0.5 \mathrm{ml}$ plasma was added and the colour estimated with a Unicam spectrophotometer at $580 \mathrm{~m} \mu$. After the 
addition of $0.1 \mathrm{ml}$ sodium dihydrogen phosphate $(69 \mathrm{~g}$ $\mathrm{NaH}_{2} \mathrm{PO}_{4} \cdot \mathrm{H}_{2} \mathrm{O}$ to $250 \mathrm{ml}$ with distilled water), a second reading was obtained and subtracted from the first. Variation in turbidity, depth of jaundice, and mild haemolysis were thus eliminated by this method, but obviously haemolysed samples were discarded. Standard BSP solutions were treated as the test plasma. By extrapolation to zero on semi-log paper using three, eight, and 12-minute readings, the initial venous BSP level was obtained. Percentage retention at 30 minutes, disappearance half time $\left(t \frac{1}{2}\right)$, and plasma disappearance rate (PDR) were determined, the latter from the formula:

$$
\text { PDR }=\frac{0.693}{t \frac{1}{2}} \times 100
$$

Relative hepatic storage $(\mathbf{S})$ and transport maximum (Tm) for BSP were estimated by the method of Wheeler, Meltzer, and Bradley (1960). By this indirect technique, observations of biliary and hepatic venous BSP levels are unnecessary. Tests were performed after an overnight fast. Infusion of BSP was with a constant infusion pump (Bowman Process and Instruments, 15 Stone Avenue, Brooklyn, New York). Intravenous Braunule size 1 (Armour) needles were used for infusion. Two infusions of constant rate were given (Adams, Gordon, and Combes, 1966) (Tables IV to VI). These were continued for at least 30 minutes before venous sampling was started; this consisted of four or five samples taken from the opposite arm over the next 20-30 minutes. When serial estimations were performed in the same patient, the rates of infusion were as far as possible identical on the two occasions. The rates of infusion were calculated to maintain an approximately constant level of plasma BSP. From the rates of change of plasma BSP and an estimated plasma volume, hepatic storage (S) (mg BSP stored/mg liver tissue $/ 100 \mathrm{ml}$ plasma BSP) and transport maximum (Tm) (mg BSP excreted/minute) were calculated from the simultaneous equations:

$$
\begin{aligned}
& \mathrm{I}_{1}=\mathrm{Tm}+\triangle \mathbf{P}_{1}(\mathrm{~S}+\mathrm{PV}) \\
& \mathbf{I}_{\mathbf{2}}=\mathrm{Tm}+\triangle \mathbf{P}_{\mathbf{2}}(\mathbf{S}+\mathbf{P V})
\end{aligned}
$$

where $I_{1}$ and $I_{2}$ are the infusion rates of BSP, $\triangle P_{1}$ and $\triangle P_{2}$ the rates of change of plasma BSP during the two infusions, and PV the plasma volume, calculated from the formula (Wheeler et al., 1960):

$$
\mathrm{PV}(\mathrm{ml})=41.2 \times \text { body weight in } \mathrm{kg}
$$

Chromatographic studies of plasma BSP were made on samples taken at three, eight, 12, 20,30, and 45 minutes after the intravenous injection of BSP by a method based on that of Javitt, Wheeler, Baker, Ramos, and Bradley (1960). Two ml plasma samples were deproteinized by mixing with $8.0 \mathrm{ml}$ acetone and centrifugation. The supernatant fluid was separated and slowly evaporated to dryness. The residue after the addition of $0.1 \mathrm{ml}$ distilled water was subjected to ascending chromatography on Whatman no. 4 paper in a solvent system of $n$-butanol: glacial acetic acid; distilled water at a ratio 4 : $1: 2$. Chromatograms were rapidly dried, sprayed with $20 \%$ potassium carbonate, and photographed. A fast moving component was repeatedly shown to be identical with commercially produced BSP. Several slower moving components were conjugates of BSP with glutathione and to a lesser extent glycine, glutamic acid, and cysteine
(Grodsky, Carbone, and Fanska, 1959; Javitt, Wheeler, Baker, and Ramos, 1959). The spots were separately eluted with the alkaline buffer used for the plasma BSP estimation and the relative concentrations of conjugated and unconjugated BSP were obtained. Absolute values for conjugated and unconjugated BSP were obtained by reference to total plasma BSP.

Total and conjugated bilirubin were estimated by a modification of the method of Michaëlsson (1961), serum aspartate transaminase by that of Reitman and Frankel (1957), and alkaline phosphatase by that of Bell and Collier (1964). Serum proteins (albumin and globulin) were measured by the method of Wolfson, Cohn, Calvary, and Ichiba (1948). The biochemical tests were done on the same day as one or more of the BSP estimations.

Hepatic histology was assessed in all patients from aspiration biopsy specimens. 'Activity', which was based on the severity of necrosis and inflammatory cell infiltration, was divided into four grades, namely,,+++++ , + and 0 .

\section{RESULTS}

BROMSULPHTHALEIN DISAPPEARANCE CURVES IN PATIENTS WITH ACTIVE CHRONIC HEPATITIS IN THE CONTROLLED TRIAL Tables I and II give results of BSP disappearance following intravenous injection in the patients in the controlled trial. In the corticosteroid group, liver histology from four patients was graded +++ and from six ++ ; eight had well developed cirrhosis. In the control group six were graded +++ and six $++; 10$ had cirrhosis. Expressed as BSP retention at 30 minutes, nine patients in the corticosteroid group (mean $38.4 \%$ ) and all of those in the control group (mean $42.9 \%$ ) had abnormal results before inclusion in the trial (Fig. 1). Expressed as plasma disappearance rate (PDR) only two patients, in the corticosteroid group, had normal results (Schoenfield, McGill, and Foulk, 1964); the mean values were 5.4 (2.8-12.6) $\% / \mathrm{min}$ and $4.3(2 \cdot 5-8 \cdot 7) \% / \mathrm{min}$ respectively. In the treated group, all except one patient had a decrease in BSP retention after starting corticosteroids. Six control patients showed a decrease and six an increase in retention. The mean reduction in the 30 minutes' BSP retention when the first and last measurements were compared was significantly greater in the corticosteroid than in the control group $(\mathrm{P}<0.02)$. There was not a significant correlation between change in BSP retention and the degree of histological activity or presence of cirrhosis. The difference between the mean increase in PDR was not significant $(P<0 \cdot 20)$. Plasma BSP at zero time was estimated by extrapolation of the disappearance curve on semi-log paper (Tables I and II). Mean values were $8.3 \mathrm{mg} / 100 \mathrm{ml}$ in the corticosteroid and $7.7 \mathrm{mg} / 100 \mathrm{ml}$ in the control group. At the last BSP determination this value was higher 
TABLE I

BROMSULPHTHALEIN (BSP) DISAPPEARANCE AFTER AN INTRAVENOUS INJECTION OF $5.0 \mathrm{mg} / \mathrm{kg}$ BODY WEIGHT IN THE 'CORTICOSTEROID' GROUP (OF THE CONTROLLED TRIAL) AND BIOCHEMICAL INDICES

\begin{tabular}{|c|c|c|c|c|c|c|c|c|c|c|c|}
\hline $\begin{array}{l}\text { Case } \\
\text { No. }\end{array}$ & Sex & $\begin{array}{c}\text { Age } \\
(y r)\end{array}$ & $\begin{array}{l}\text { Time } \\
\text { after } \\
\text { Inclusion } \\
\text { in Trial } \\
\text { (weeks) }\end{array}$ & $\begin{array}{l}\text { BSP } \\
\text { Retention } \\
\text { at } 30 \\
\text { Minutes } \\
(\% \text { of } \\
\text { initial dose) }\end{array}$ & $\begin{array}{l}\text { Plasma } \\
\text { Disappear- } \\
\text { ance Rate } \\
(P D R) \\
(\% / \text { min })\end{array}$ & $\begin{array}{l}\text { Plasma BSP } \\
\text { Level at } \\
\text { Zero Time } \\
(\mathrm{mg} / 100 \mathrm{ml})\end{array}$ & $\begin{array}{l}\text { Serum } \\
\text { Bilirubin } \\
(\mathrm{mg} / \\
100 \mathrm{ml})\end{array}$ & $\begin{array}{l}\text { Serum } \\
\text { Aspartate } \\
\text { Transami- } \\
\text { nase } \\
(\text { AST }) \\
(\text { iullitre })^{2}\end{array}$ & $\begin{array}{l}\text { Alkaline } \\
\text { Phosphat- } \\
\text { ase }(\text { KA } \\
\text { units } \\
100 \mathrm{ml})\end{array}$ & $\begin{array}{l}\text { Serum } \\
\text { Albumin } \\
(\mathrm{g} / 100 \mathrm{ml})\end{array}$ & $\begin{array}{l}\text { Serum } \\
\text { Total } \\
\text { Globulin } \\
(\mathrm{g} / 100 \mathrm{ml})\end{array}$ \\
\hline 1 & $\mathbf{F}$ & 46 & $\begin{array}{r}0 \\
2 \\
4 \\
6 \\
36 \\
76\end{array}$ & $\begin{array}{l}48 \cdot 3 \\
43 \cdot 1 \\
30 \cdot 6 \\
31 \cdot 5 \\
22 \cdot 6 \\
18 \cdot 2\end{array}$ & $\begin{array}{l}2 \cdot 9 \\
4 \cdot 1 \\
5 \cdot 3 \\
6 \cdot 3 \\
6 \cdot 3 \\
6 \cdot 9\end{array}$ & $\begin{array}{r}11 \cdot 7 \\
10 \cdot 6 \\
10 \cdot 7 \\
8 \cdot 8 \\
8 \cdot 0 \\
9 \cdot 5\end{array}$ & $4 \cdot 2$ & 92 & 12 & $2 \cdot 3$ & $4 \cdot 2$ \\
\hline 2 & $\mathbf{M}$ & 15 & $\begin{array}{r}0 \\
1 \\
5 \\
13\end{array}$ & $\begin{array}{l}46 \cdot 1 \\
40 \cdot 1 \\
40 \cdot 8 \\
20 \cdot 5\end{array}$ & $\begin{array}{l}3 \cdot 2 \\
4 \cdot 1 \\
5 \cdot 3 \\
8 \cdot 7\end{array}$ & $\begin{array}{l}6 \cdot 4 \\
7 \cdot 8 \\
7 \cdot 6 \\
8 \cdot 7\end{array}$ & 1.6 & 172 & $\begin{array}{l}30 \\
19\end{array}$ & $\begin{array}{l}3 \cdot 6 \\
3 \cdot 8\end{array}$ & 5.7 \\
\hline 3 & $\mathbf{F}$ & 8 & $\begin{array}{r}0 \\
51\end{array}$ & $\begin{array}{l}5.0 \\
3.9\end{array}$ & $\begin{array}{l}12.6 \\
13.9\end{array}$ & $\begin{array}{l}9.0 \\
8.4\end{array}$ & $\begin{array}{l}1.2 \\
0.5\end{array}$ & $\begin{array}{r}64 \\
6\end{array}$ & $\begin{array}{l}22 \\
19\end{array}$ & $\begin{array}{l}4 \cdot 1 \\
5 \cdot 2\end{array}$ & $\begin{array}{l}4 \cdot 4 \\
3 \cdot 4\end{array}$ \\
\hline 4 & $\mathbf{F}$ & 51 & $\begin{array}{r}0 \\
3 \\
7 \\
11 \\
35 \\
67\end{array}$ & $\begin{array}{l}52 \cdot 0 \\
48 \cdot 0 \\
52 \cdot 3 \\
50 \cdot 7 \\
50 \cdot 0 \\
59 \cdot 2\end{array}$ & $\begin{array}{l}2 \cdot 8 \\
4 \cdot 3 \\
3 \cdot 2 \\
3 \cdot 7 \\
3 \cdot 2 \\
2 \cdot 2\end{array}$ & $\begin{array}{l}8 \cdot 8 \\
7 \cdot 4 \\
6 \cdot 5 \\
7 \cdot 3 \\
8 \cdot 4 \\
8 \cdot 3\end{array}$ & $22 \cdot 0$ & 70 & 38 & $3 \cdot 3$ & 3.9 \\
\hline 5 & $\mathbf{F}$ & 50 & $\begin{array}{r}0 \\
6 \\
10 \\
26\end{array}$ & $\begin{array}{l}53 \cdot 5 \\
43 \cdot 7 \\
34 \cdot 4 \\
16 \cdot 6\end{array}$ & $\begin{array}{l}2 \cdot 8 \\
3 \cdot 5 \\
5 \cdot 3 \\
8 \cdot 1\end{array}$ & $\begin{array}{l}10 \cdot 2 \\
10 \cdot 4 \\
10 \cdot 8 \\
11 \cdot 0\end{array}$ & $\begin{array}{l}2.5 \\
0.5\end{array}$ & $\begin{array}{r}130 \\
25\end{array}$ & $\begin{array}{l}32 \\
11\end{array}$ & $\begin{array}{l}2 \cdot 2 \\
3 \cdot 6\end{array}$ & $\begin{array}{l}5.6 \\
2.5\end{array}$ \\
\hline 6 & $\mathbf{F}$ & 56 & $\begin{array}{r}0 \\
4 \\
12 \\
54\end{array}$ & $\begin{array}{l}51 \cdot 4 \\
28 \cdot 9 \\
34 \cdot 2 \\
30 \cdot 1\end{array}$ & $\begin{array}{l}3 \cdot 1 \\
6 \cdot 3 \\
4 \cdot 8 \\
7 \cdot 3\end{array}$ & $\begin{array}{r}7 \cdot 2 \\
9 \cdot 0 \\
8 \cdot 8 \\
12 \cdot 0\end{array}$ & 0.8 & 15 & $\begin{array}{l}20 \\
14\end{array}$ & $\begin{array}{l}2 \cdot 5 \\
4 \cdot 0\end{array}$ & $\begin{array}{l}6.5 \\
4.9\end{array}$ \\
\hline 7 & $\mathbf{M}$ & 51 & $\begin{array}{l}0 \\
0 \\
4\end{array}$ & $\begin{array}{l}37 \cdot 8 \\
41 \cdot 7 \\
22 \cdot 0\end{array}$ & $\begin{array}{l}5.8 \\
4.9 \\
7 \cdot 7\end{array}$ & $\begin{array}{l}7 \cdot 9 \\
8 \cdot 1 \\
8 \cdot 3\end{array}$ & $\begin{array}{l}2.0 \\
1.4\end{array}$ & $\begin{array}{l}51 \\
27\end{array}$ & $\begin{array}{l}44 \\
40\end{array}$ & $\begin{array}{l}2.7 \\
3.6\end{array}$ & $\begin{array}{l}5.9 \\
6.0\end{array}$ \\
\hline 8 & $\mathbf{F}$ & 23 & $\begin{array}{r}0 \\
3 \\
11\end{array}$ & $\begin{array}{l}38 \cdot 0 \\
20 \cdot 8 \\
16 \cdot 3\end{array}$ & $\begin{array}{l}5.5 \\
9 \cdot 2 \\
8 \cdot 7\end{array}$ & $\begin{array}{l}7 \cdot 5 \\
7 \cdot 3 \\
7 \cdot 0\end{array}$ & $\begin{array}{l}2.2 \\
0.5\end{array}$ & $\begin{array}{r}160 \\
40\end{array}$ & $\begin{array}{l}47 \\
24\end{array}$ & $\begin{array}{l}4 \cdot 0 \\
3 \cdot 3\end{array}$ & $\begin{array}{l}4 \cdot 6 \\
4 \cdot 6\end{array}$ \\
\hline 9 & $\mathbf{F}$ & 15 & $\begin{array}{r}0 \\
16\end{array}$ & $\begin{array}{l}30 \cdot 1 \\
19 \cdot 7\end{array}$ & $\begin{array}{l}5.3 \\
6.9\end{array}$ & $\begin{array}{l}7.5 \\
9.5\end{array}$ & $\begin{array}{l}1.7 \\
0.7\end{array}$ & $\begin{array}{r}500 \\
25\end{array}$ & $\begin{array}{l}6 \\
8\end{array}$ & $\begin{array}{l}2.9 \\
3.5\end{array}$ & $\begin{array}{l}7 \cdot 7 \\
5 \cdot 3\end{array}$ \\
\hline 10 & $\mathbf{F}$ & 51 & $\begin{array}{l}0 \\
2 \\
6\end{array}$ & $\begin{array}{l}22 \cdot 3 \\
22 \cdot 6 \\
20 \cdot 8\end{array}$ & $\begin{array}{r}9.9 \\
9.9 \\
10.7\end{array}$ & $\begin{array}{l}6.6 \\
7.0 \\
8.8\end{array}$ & $\begin{array}{l}1.5 \\
1.0\end{array}$ & $\begin{array}{l}35 \\
28\end{array}$ & $\begin{array}{r}70 \\
75\end{array}$ & $\begin{array}{l}2.2 \\
2.5\end{array}$ & $\begin{array}{l}7 \cdot 4 \\
5 \cdot 0\end{array}$ \\
\hline
\end{tabular}

${ }^{1}$ For each patient, the first estimation was done immediately before starting corticosteroids.

${ }^{2}$ Normal range $<17$ i.u./litre.

than the first in six patients in the corticosteroid and 10 in the control group; the difference is not significant. Serum bilirubin, aspartate transaminase, alkaline phosphatase, and albumin and globulin values at the initial and last BSP estimation are shown in Tables I and II. The correlation coefficient (r) between change in BSP retention and change in serum bilirubin was $+0.456(\mathrm{P}<0.05)$; that between BSP retention and serum aspartate transaminase $+0.514(P<0.02)$; and that between BSP retention and serum total globulin $+0.597(\mathrm{P}<0.01)$. Changes in BSP retention in the patients in both groups therefore occurred pari passu with changes in the biochemical indices of 'activity' of the hepatic lesion.

STORAGE (s) AND TRANSPORT MAXIMUM (Tm) IN PATIENTS WITH ACTIVE CHRONIC HEPATITIS Table III summarizes the results of single $\mathrm{S}$ and Tm estimations in 24 patients with active chronic hepatitis. Fourteen were receiving corticos teroids and 10 were not being treated. The degree of histological activity in the patients receiving prednisolone was +++ in four, ++ in six, and + in four; all except one had 
TABLE II

BROMSULPHTHALEIN (BSP) DISAPPEARANCE AFTER AN INTRAVENOUS INJECTION OF $5.0 \mathrm{mg} / \mathrm{kg}$ BODY WEIGHT IN THE 'CONTROL' GROUP (OF THE CONTROLLED TRIAL) AND BIOCHEMICAL INDICES

\begin{tabular}{|c|c|c|c|c|c|c|c|c|c|c|c|}
\hline $\begin{array}{l}\text { Case } \\
\text { No. }\end{array}$ & Sex & $\begin{array}{c}\text { Age } \\
(y r)\end{array}$ & $\begin{array}{l}\text { Time after } \\
\text { Inclusion } \\
\text { in Controlled } \\
\text { Trial (weeks) }\end{array}$ & $\begin{array}{l}\text { BSP } \\
\text { Retention } \\
\text { at } 30 \\
\text { Minutes } \\
(\% \text { of } \\
\text { initial dose })\end{array}$ & $\begin{array}{l}\text { Plasma } \\
\text { Disappear- } \\
\text { ance Rate } \\
(P D R) \\
(\% / \text { min })\end{array}$ & $\begin{array}{l}\text { Plasma BSP } \\
\text { Level at } \\
\text { Zero Time } \\
(\mathrm{mg} / 100 \mathrm{ml})\end{array}$ & $\begin{array}{l}\text { Serum } \\
\text { Bilirubin } \\
(\mathrm{mg} / \\
100 \mathrm{ml})\end{array}$ & $\begin{array}{l}\text { Serum } \\
\text { Transami- } \\
\text { nase }(A S T) \\
\text { (iullitre) }\end{array}$ & $\begin{array}{l}\text { Alkaline } \\
\text { Phosphat- } \\
\text { ase }(K A \\
\text { unitsl } \\
100 \mathrm{ml})\end{array}$ & $\begin{array}{l}\text { Serum } \\
\text { Albumin } \\
(\mathrm{g} / 100 \mathrm{ml})\end{array}$ & $\begin{array}{l}\text { Serum } \\
\text { Total } \\
\text { Globulin } \\
(\mathrm{g} / 100 \mathrm{ml})\end{array}$ \\
\hline 11 & $\mathbf{M}$ & 24 & $\begin{array}{r}0 \\
10 \\
23\end{array}$ & $\begin{array}{r}11.9 \\
7.8 \\
5.0\end{array}$ & $\begin{array}{r}8 \cdot 7 \\
10 \cdot 7 \\
17 \cdot 3\end{array}$ & $\begin{array}{r}9.6 \\
10 \cdot 0 \\
10.0\end{array}$ & $\begin{array}{l}2 \cdot 0 \\
0.3\end{array}$ & $\begin{array}{r}116 \\
15\end{array}$ & $\begin{array}{l}16 \\
32\end{array}$ & $\begin{array}{l}4 \cdot 2 \\
4 \cdot 4\end{array}$ & $\begin{array}{l}3 \cdot 8 \\
3 \cdot 1\end{array}$ \\
\hline 12 & $\mathbf{F}$ & 47 & $\begin{array}{r}0 \\
2 \\
14 \\
45\end{array}$ & $\begin{array}{l}25 \cdot 5 \\
20 \cdot 2 \\
13.9 \\
11.9\end{array}$ & $\begin{array}{l}6 \cdot 3 \\
6 \cdot 9 \\
7 \cdot 7 \\
9 \cdot 2\end{array}$ & $\begin{array}{l}7 \cdot 7 \\
8 \cdot 9 \\
9 \cdot 0 \\
9 \cdot 1\end{array}$ & 0.7 & $\begin{array}{l}34 \\
19\end{array}$ & $\begin{array}{l}11 \\
14\end{array}$ & $\begin{array}{l}3 \cdot 1 \\
4 \cdot 9\end{array}$ & $\begin{array}{l}5 \cdot 4 \\
2 \cdot 8\end{array}$ \\
\hline 13 & $\mathbf{F}$ & 15 & $\begin{array}{l}0 \\
4\end{array}$ & $\begin{array}{l}51 \cdot 2 \\
55 \cdot 8\end{array}$ & $\begin{array}{l}3.5 \\
2.5\end{array}$ & $\begin{array}{l}8 \cdot 1 \\
8 \cdot 5\end{array}$ & $\begin{array}{l}5 \cdot 1 \\
3 \cdot 8\end{array}$ & $\begin{array}{l}195 \\
230\end{array}$ & $\begin{array}{l}27 \\
28\end{array}$ & $\begin{array}{l}2.2 \\
2.6\end{array}$ & $\begin{array}{l}9 \cdot 2 \\
9 \cdot 4\end{array}$ \\
\hline 14 & $\mathbf{F}$ & 61 & $\begin{array}{l}0 \\
6\end{array}$ & $\begin{array}{l}43 \cdot 6 \\
49 \cdot 5\end{array}$ & $\begin{array}{l}3 \cdot 5 \\
3 \cdot 1\end{array}$ & $\begin{array}{l}8 \cdot 6 \\
9 \cdot 1\end{array}$ & $\begin{array}{l}7.0 \\
8.0\end{array}$ & $\begin{array}{l}170 \\
290\end{array}$ & $\begin{array}{l}34 \\
23\end{array}$ & $\begin{array}{l}1.3 \\
1.4\end{array}$ & $\begin{array}{l}6 \cdot 6 \\
7 \cdot 2\end{array}$ \\
\hline 15 & $\mathbf{M}$ & 31 & $\begin{array}{r}0 \\
11 \\
29 \\
49 \\
78\end{array}$ & $\begin{array}{l}37 \cdot 9 \\
45 \cdot 3 \\
45 \cdot 1 \\
42 \cdot 0 \\
46 \cdot 2\end{array}$ & $\begin{array}{l}5 \cdot 8 \\
4 \cdot 2 \\
4 \cdot 0 \\
4 \cdot 8 \\
4 \cdot 6\end{array}$ & $\begin{array}{l}6 \cdot 6 \\
6 \cdot 8 \\
6 \cdot 2 \\
6 \cdot 1 \\
7 \cdot 9\end{array}$ & 4.4 & 115 & 120 & 2.5 & $6 \cdot 2$ \\
\hline 16 & $\mathbf{F}$ & 27 & $\begin{array}{r}0 \\
43\end{array}$ & $\begin{array}{l}45 \cdot 3 \\
43 \cdot 7\end{array}$ & $\begin{array}{l}3 \cdot 4 \\
4 \cdot 2\end{array}$ & $\begin{array}{l}7.8 \\
8.7\end{array}$ & $\begin{array}{l}1.0 \\
2.0\end{array}$ & $\begin{array}{l}44 \\
26\end{array}$ & $\begin{array}{l}29 \\
30\end{array}$ & $\begin{array}{l}2.5 \\
2.6\end{array}$ & $\begin{array}{l}4 \cdot 3 \\
4 \cdot 5\end{array}$ \\
\hline 17 & $\mathbf{F}$ & 11 & $\begin{array}{r}0 \\
56\end{array}$ & $\begin{array}{l}55 \cdot 1 \\
41 \cdot 9\end{array}$ & $\begin{array}{l}3 \cdot 1 \\
4 \cdot 3\end{array}$ & $\begin{array}{l}6 \cdot 3 \\
7 \cdot 4\end{array}$ & $\begin{array}{l}4.5 \\
2.6\end{array}$ & $\begin{array}{l}95 \\
65\end{array}$ & $\begin{array}{l}44 \\
40\end{array}$ & $\begin{array}{r}3.0 \\
2.4\end{array}$ & $\begin{array}{l}6 \cdot 7 \\
6 \cdot 1\end{array}$ \\
\hline 18 & $\mathbf{M}$ & 44 & $\begin{array}{l}0 \\
9\end{array}$ & $\begin{array}{l}49 \cdot 4 \\
55 \cdot 3\end{array}$ & $\begin{array}{l}3 \cdot 1 \\
2 \cdot 6\end{array}$ & $\begin{array}{l}8.5 \\
7.5\end{array}$ & $\begin{array}{l}2 \cdot 3 \\
2 \cdot 3\end{array}$ & $\begin{array}{l}110 \\
135\end{array}$ & $\begin{array}{l}33 \\
23\end{array}$ & $\begin{array}{l}2 \cdot 1 \\
2 \cdot 2\end{array}$ & $\begin{array}{l}4 \cdot 2 \\
7 \cdot 3\end{array}$ \\
\hline 19 & $\mathbf{F}$ & 50 & $\begin{array}{r}0 \\
4 \\
10 \\
24\end{array}$ & $\begin{array}{l}51 \cdot 7 \\
52 \cdot 8 \\
48 \cdot 3 \\
29 \cdot 4\end{array}$ & $\begin{array}{l}3 \cdot 1 \\
2 \cdot 9 \\
3 \cdot 3 \\
5 \cdot 1\end{array}$ & $\begin{array}{r}8 \cdot 5 \\
9 \cdot 0 \\
10 \cdot 2 \\
12 \cdot 6\end{array}$ & $\begin{array}{l}11.0 \\
0.6\end{array}$ & $\begin{array}{l}310 \\
19\end{array}$ & $\begin{array}{l}45 \\
12\end{array}$ & $\begin{array}{l}3 \cdot 3 \\
4 \cdot 3\end{array}$ & $\begin{array}{l}5 \cdot 1 \\
3 \cdot 7\end{array}$ \\
\hline 20 & $\mathbf{F}$ & 48 & $\begin{array}{r}0 \\
5 \\
16 \\
20 \\
29\end{array}$ & $\begin{array}{l}51.4 \\
48.9 \\
51 \cdot 3 \\
47.4 \\
52.8\end{array}$ & $\begin{array}{l}3 \cdot 1 \\
3 \cdot 5 \\
3 \cdot 1 \\
3 \cdot 4 \\
2 \cdot 7\end{array}$ & $\begin{array}{l}7 \cdot 0 \\
8 \cdot 4 \\
7 \cdot 2 \\
6 \cdot 6 \\
7 \cdot 1\end{array}$ & $2 \cdot 3$ & 26 & 46 & 3.8 & 3.7 \\
\hline 21 & $\mathbf{F}$ & 57 & $\begin{array}{l}0 \\
8\end{array}$ & $\begin{array}{l}33 \cdot 5 \\
34 \cdot 6\end{array}$ & $\begin{array}{l}5 \cdot 8 \\
5 \cdot 1\end{array}$ & $\begin{array}{l}8 \cdot 3 \\
7 \cdot 8\end{array}$ & $\begin{array}{l}2 \cdot 6 \\
2 \cdot 2\end{array}$ & $\begin{array}{l}49 \\
45\end{array}$ & $\begin{array}{l}46 \\
54\end{array}$ & $\begin{array}{l}3 \cdot 0 \\
3 \cdot 4\end{array}$ & $\begin{array}{l}5 \cdot 6 \\
4 \cdot 5\end{array}$ \\
\hline 22 & $\mathbf{M}$ & 39 & $\begin{array}{l}0 \\
8\end{array}$ & $\begin{array}{l}58.9 \\
56.5\end{array}$ & $\begin{array}{l}2 \cdot 5 \\
3 \cdot 1\end{array}$ & $\begin{array}{l}5.5 \\
7.9\end{array}$ & $\begin{array}{l}3.9 \\
5.2\end{array}$ & $\begin{array}{r}61 \\
151\end{array}$ & $\begin{array}{l}17 \\
17\end{array}$ & $\begin{array}{l}3.0 \\
2.2\end{array}$ & $\begin{array}{l}5.7 \\
5.6\end{array}$ \\
\hline
\end{tabular}

\section{TABLE III}

SUMMARY OF THE MEAN STORAGE (s) AND TRANSPORT MAXIMUM (Tm) FOR BSP AND BIOCHEMICAL INDICES IN PATIENTS WITH ACTIVE CHRONIC HEPATITIS WITH ONLY ONE ESTIMATION

\begin{tabular}{|c|c|c|c|c|c|c|c|c|c|c|c|c|}
\hline \multirow[t]{2}{*}{ Group } & \multirow{2}{*}{$\begin{array}{l}\text { No. } \\
\text { Stud- } \\
\text { ied }\end{array}$} & \multicolumn{2}{|c|}{ Sex } & \multirow{2}{*}{$\begin{array}{l}\text { Age }(y r) \\
\text { (Mean and } \\
\text { Range) }\end{array}$} & \multirow{2}{*}{$\begin{array}{l}\text { Storage (S) } \\
(\mathrm{mg} / \mathrm{mg} / \\
100 \mathrm{ml})\end{array}$} & \multirow{2}{*}{$\begin{array}{l}\text { Transport } \\
\text { Maximum } \\
(T m) \\
(m g / m i n)\end{array}$} & \multirow[t]{2}{*}{$S / T m$} & \multirow{2}{*}{$\begin{array}{l}\text { Serum } \\
\text { Bilirubin } \\
(\mathrm{mg} / 100 \mathrm{ml})\end{array}$} & \multirow{2}{*}{$\begin{array}{l}\text { Serum } \\
\text { Aspartate } \\
\text { l) Trans- } \\
\text { aminase } \\
\text { (iu/litre) }\end{array}$} & \multirow{2}{*}{$\begin{array}{l}\text { Serum } \\
\text { Alkaline } \\
\text { Phos- } \\
\text { phatase } \\
(\text { KA units/ } \\
100 \mathrm{ml})\end{array}$} & \multirow{2}{*}{$\begin{array}{l}\text { Serum } \\
\text { Albumin } \\
(\mathrm{g} / 100 \mathrm{ml})\end{array}$} & \multirow{2}{*}{$\begin{array}{l}\text { Serum } \\
\text { Total } \\
\text { Globulin } \\
(\mathrm{g} / 100 \mathrm{ml})\end{array}$} \\
\hline & & $M$ & $F$ & & & & & & & & & \\
\hline $\begin{array}{l}\text { Receiving } \\
\text { corticos- } \\
\text { teroids at } \\
\text { time of test }\end{array}$ & 14 & 5 & 9 & $\begin{array}{l}31 \\
(10-60)\end{array}$ & $\begin{array}{l}30 \cdot 6 \\
(9 \cdot 0-67 \cdot 8)\end{array}$ & $\begin{array}{l}4 \cdot 3 \\
(2 \cdot 2-7 \cdot 3)\end{array}$ & $\begin{array}{l}7 \cdot 8 \\
(2 \cdot 6-14 \cdot 1)\end{array}$ & $\begin{array}{l}3 \cdot 2 \\
(0 \cdot 5-22 \cdot 5)\end{array}$ & $\begin{array}{l}45 \\
(10-108)\end{array}$ & $\begin{array}{l}22 \cdot 7 \\
(5-67)\end{array}$ & $\begin{array}{l}3 \cdot 8 \\
(2 \cdot 9 \cdot 4 \cdot 6)\end{array}$ & $\begin{array}{l}3 \cdot 9 \\
(2 \cdot 6-5 \cdot 4)\end{array}$ \\
\hline $\begin{array}{l}\text { No } \\
\text { corticos- } \\
\text { teroids }\end{array}$ & 10 & 2 & 8 & $\begin{array}{l}49 \\
(11-74)\end{array}$ & $\begin{array}{l}40 \cdot 2 \\
(16 \cdot 7-69 \cdot 1)\end{array}$ & $\begin{array}{l}3 \cdot 9 \\
(2 \cdot 6-6 \cdot 2)\end{array}$ & $\begin{array}{l}10 \cdot 7 \\
(5 \cdot 8-21 \cdot 7)\end{array}$ & $\begin{array}{l}1 \cdot 3 \\
(0 \cdot 5-2 \cdot 3)\end{array}$ & $\begin{array}{l}30 \\
(10-52)\end{array}$ & $\begin{array}{l}26 \cdot 3 \\
(8-79)\end{array}$ & $\begin{array}{l}3 \cdot 2 \\
(1 \cdot 7-4 \cdot 3)\end{array}$ & $\begin{array}{l}4 \cdot 2 \\
(2 \cdot 0-6 \cdot 2)\end{array}$ \\
\hline
\end{tabular}




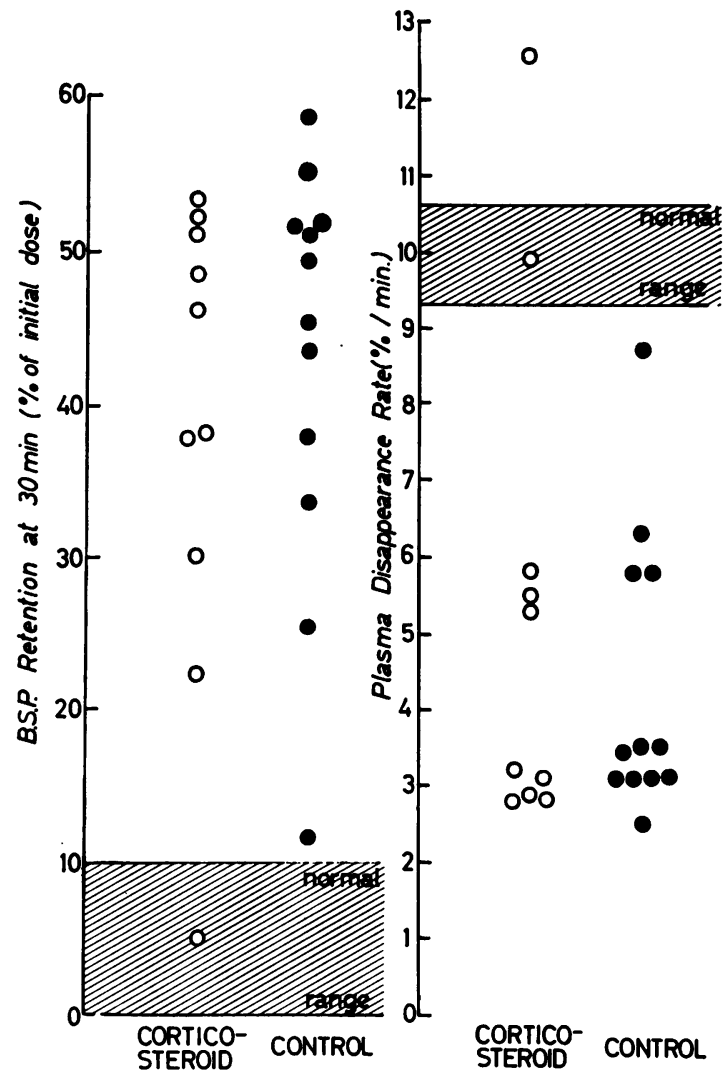

FIG. 1. Initial bromsulphthalein (BSP) retention at 30 minutes and plasma disappearance rate $(P D R)$ after an intravenous injection of $5.0 \mathrm{mg}$ per $\mathrm{kg}$ body weight in two randomly selected groups of patients with active chronic hepatitis before inclusion in the controlled therapeutic trial. The hatched areas indicate normal ranges.

cirrhosis. In the untreated group, one patient was graded +++ , four ++ , and five + ; all except one had cirrhosis. The differences between the mean storage (S), transport maximum $(\mathrm{Tm})$ and $S / T m$ ratio between the two groups is not significant. There is a significant correlation between storage (S) and serum aspartate transaminase $(r=-0.545 ; P<0.01)$ in the individuals of both groups. The correlation between storage (S) and serum bilirubin $(r=-0 \cdot 224)$, and storage and serum total globulin $(r=-0 \cdot 116)$ is not significant. The correlation between transport maximum (Tm) and serum alkaline phosphatase $(r=-0.558)$ is significant $(P<0.01)$.

Tables IV and V summarize results of serial estimations of BSP storage and transport maximum. Results for initial $\mathbf{S}$ and $\mathrm{Tm}$ values are compared in Figure 2. Mean levels for $S$ were 26.5 (5.4-50.0) $\mathrm{mg} / \mathrm{mg} / 100 \mathrm{ml}$ in the group subsequently treated with prednisolone, and $35.0(21 \cdot 8-58.0) \mathrm{mg} / \mathrm{mg} /$
$100 \mathrm{ml}$ in the control group. Those for Tm were $3.9(2.2-7.0) \mathrm{mg} / \mathrm{min}$ and $4.8(1.4-11.2) \mathrm{mg} / \mathrm{min}$ respectively. Mean $\mathrm{S} / \mathrm{Tm}$ ratios were $7.8(1.3-$ $18.5)$ and $9 \cdot 3(3 \cdot 3-18 \cdot 3)$. The change in storage (S) between the first and last determinations in the two groups is shown in Fig. 3; the mean increase in $\mathbf{S}$ is significantly greater in the group treated with prednisolone than in the control group $(\mathrm{P}<0.02)$. The change in transport maximum (Tm) between

\section{STORAGE(S)}

TRANSPORT MAXIMUM(Tm)
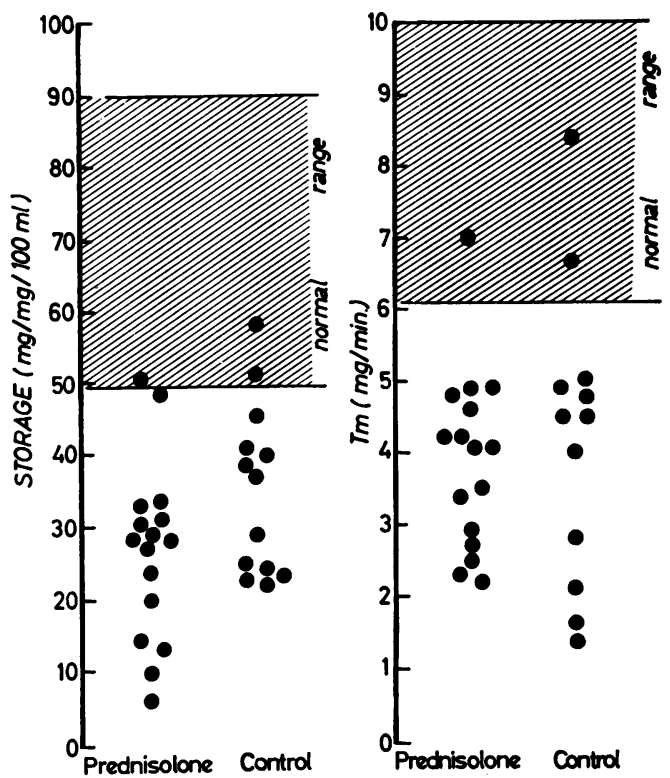

FIG. 2. Initial values for storage (S) and transport maximum (Tm) for BSP in 'prednisolone' and 'control' groups of patients with active chronic hepatitis. Normal values (Williams, 1965) are indicated by the hatched areas.

the first and last estimations is, however, not significantly different between the two groups $(\mathbf{P}>$ $0 \cdot 10)$ (Fig. 4). The percentage change in $S / T m$ is also not significantly different between the groups $(P<0 \cdot 10)$. Figure 5 summarizes the results of BSP storage (S) and Tm changes in a patient with active chronic hepatitis who was treated with prednisolone (patient no. K). Values for other biochemical indices were also estimated at the same time as $\mathbf{S}$ and Tm determinations (Tables IV and V). A significant correlation exists between percentage change in storage (S) and change in serum bilirubin $(r=-0.461 ; P<0.05)$, and between change in storage (S) and change in serum total globulin 

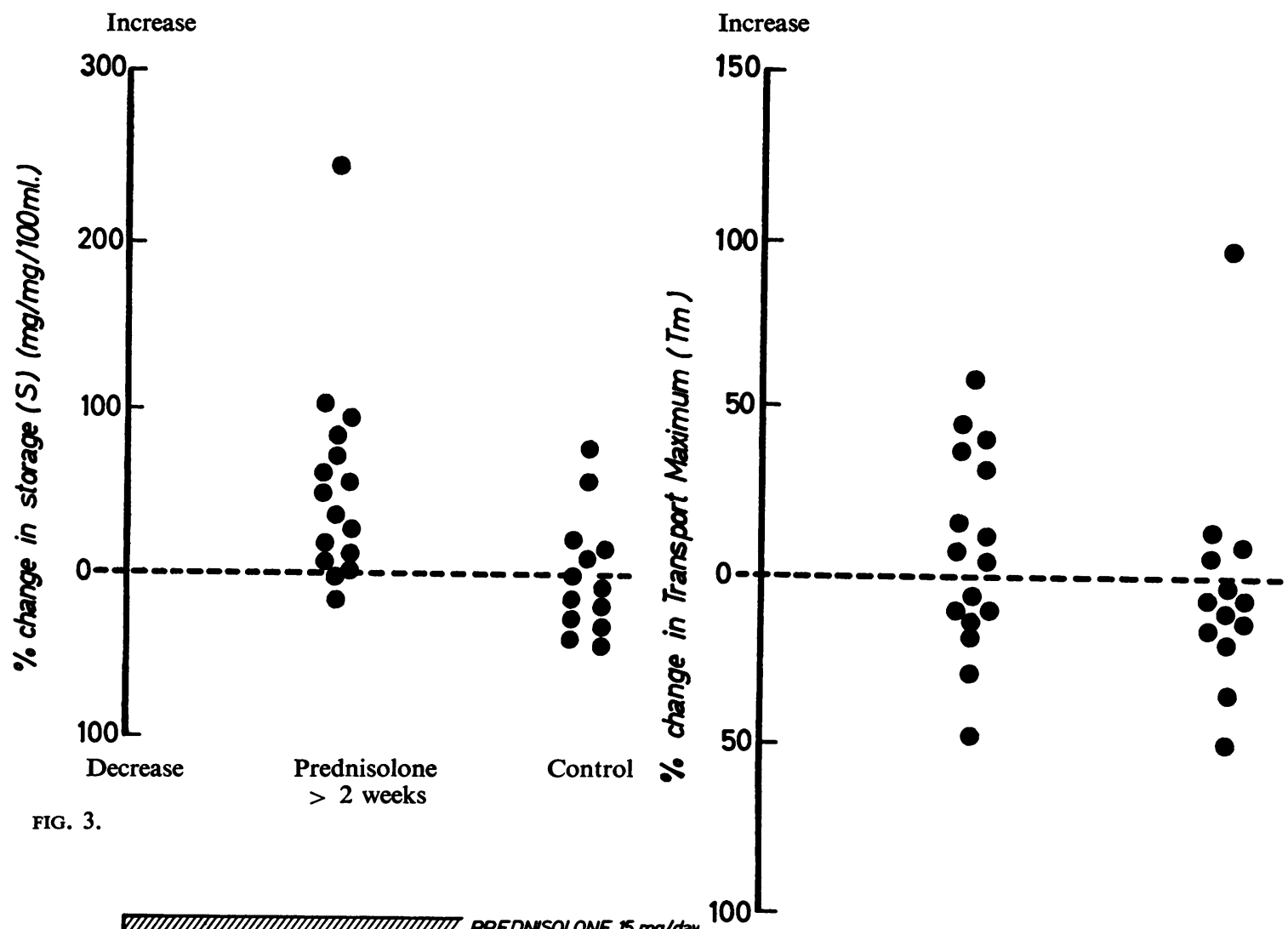
TIIIIIIIIIIIIIIIIIIIIIII PREDNSOLONE $15 \mathrm{mg} /$ day
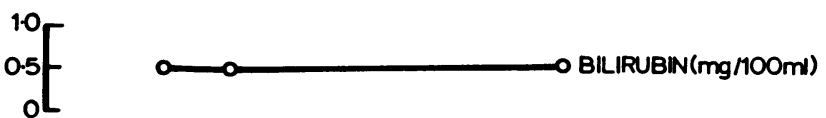
Decrease Prednisolone Control FIG. 4.
$>2$ weeks

FIG. 5 .

FIG. 3. Percentage change in BSP storage (S) in 'prednisolone' and 'control' groups of patients with active chronic hepatitis. The difference between the means is significant $(P<0.02)$.

FIG. 4. Percentage change in transport maximum (Tm) for BSP in 'prednisolone' and 'control' groups of patients with active chronic hepatitis. The difference in the means is not significant $(P>0 \cdot 10)$.

FIG. 5. Serum bilirubin, aspartate transaminase, $B S P$ retention at 30 minutes, storage $(S)$ and transport maximum $(\mathrm{Tm})$ in a patient (no. K) with active chronic hepatitis treated with prednisolone.

TRANSPORT

MAXIMUM ( $\mathrm{mg} / \mathrm{min})$

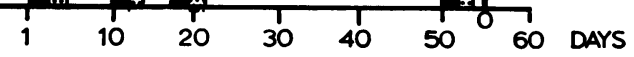




\section{TABLE IV}

SERIAL ESTIMATIONS OF STORAGE (s) AND TRANSPORT MAXIMUM (Tm) FOR BSP IN PATIENTS WITH ACTIVE CHRONIC HEPATITIS TREATED WITH CORTICOSTEROIDS (15 mg PREDNISOLONE DAILY) AND BIOCHEMICAL INDICES

\begin{tabular}{|c|c|c|c|c|c|c|c|c|c|c|c|c|c|}
\hline \multirow[t]{2}{*}{$\begin{array}{l}\text { Case } \\
\text { No. }\end{array}$} & \multirow[t]{2}{*}{$\begin{array}{c}\text { Sex Age Activity } \\
\text { (yr) of Liver } \\
\text { Histology }\end{array}$} & \multirow{2}{*}{$\begin{array}{l}\text { Inter- Body } \\
\text { val Weight } \\
\text { between }(\mathrm{kg}) \\
\text { First } \\
\text { and } \\
\text { Final } \\
\text { Estima- } \\
\text { tion }^{\mathbf{1}} \\
\text { (weeks) }\end{array}$} & \multicolumn{2}{|c|}{$\begin{array}{l}\text { Infusion } \\
\text { Rates } \\
\text { (mg BSP/min) }\end{array}$} & \multirow[t]{2}{*}{$\begin{array}{l}\text { Storage } \\
(\mathrm{S}) \\
(\mathrm{mg} / \mathrm{mg} / \\
100 \mathrm{ml})\end{array}$} & \multirow{2}{*}{\multicolumn{2}{|c|}{$\begin{array}{l}\text { Transport } S / T m \\
\text { Maxi- } \\
\operatorname{mum}(T m) \\
(\operatorname{mg} / \text { min })\end{array}$}} & \multirow[t]{2}{*}{$\begin{array}{l}\text { Serum } \\
\text { Bilirubin } \\
(m g / 100 \\
m l)\end{array}$} & \multirow{2}{*}{$\begin{array}{l}\text { Serum } \\
\text { Aspar- } \\
\text { tate } \\
\text { Trans- } \\
\text { aminase } \\
\text { (iu/ } \\
\text { litre) }\end{array}$} & \multirow{2}{*}{\multicolumn{2}{|c|}{$\begin{array}{l}\begin{array}{l}\text { Serum } \\
\text { Alkaline } \\
\text { Phos- } \\
\text { phatase } \\
(\text { KA }\end{array} \\
\text { units/ } \\
100 \mathrm{ml})\end{array}$}} & \multirow[t]{2}{*}{$\begin{array}{l}\text { Serum } \\
\text { Albumin } \\
(\mathrm{g} / 100 \\
\mathrm{ml})\end{array}$} & \multirow{2}{*}{$\begin{array}{l}\text { Serum } \\
\text { Total } \\
\text { Globuli } \\
(\mathrm{g} / 100 \\
\mathrm{ml})\end{array}$} \\
\hline & & & High & Low & & & & & & & & & \\
\hline
\end{tabular}

\begin{tabular}{|c|c|c|c|c|c|c|c|c|c|c|c|c|c|c|c|c|}
\hline a & $\mathbf{M}$ & 35 & ++ & C & 28 & $\begin{array}{l}52 \cdot 3 \\
55 \cdot 5\end{array}$ & $\begin{array}{l}11.27 \\
11.04\end{array}$ & $\begin{array}{l}1.98 \\
1.75\end{array}$ & $\begin{array}{l}27 \cdot 9 \\
33 \cdot 3\end{array}$ & $\begin{array}{l}4.6 \\
3.8\end{array}$ & $\begin{array}{l}6 \cdot 1 \\
8 \cdot 8\end{array}$ & $\begin{array}{l}2.2 \\
1.4\end{array}$ & $\begin{array}{l}24 \\
16\end{array}$ & $\begin{array}{l}19 \\
20\end{array}$ & $\begin{array}{l}2 \cdot 7 \\
2.9\end{array}$ & $\begin{array}{l}4.2 \\
3.7\end{array}$ \\
\hline \multirow[t]{2}{*}{ b } & $\mathbf{F}$ & 61 & ++ & C & 21 & $45 \cdot 7$ & 14.70 & 2.55 & 9.7 & $4 \cdot 2$ & $2 \cdot 3$ & 5.0 & 240 & 16 & $3 \cdot 4$ & $\begin{array}{l}3.1 \\
4.4\end{array}$ \\
\hline & & & & & & 55.0 & $13 \cdot 21$ & $2 \cdot 19$ & $15 \cdot 6$ & $4 \cdot 4$ & 3.5 & 1.0 & 39 & 8 & 4.6 & 3.7 \\
\hline \multirow[t]{2}{*}{ c } & $\mathbf{F}$ & 14 & ++ & C & 22 & $58 \cdot 6$ & $16 \cdot 50$ & 2.73 & $33 \cdot 5$ & $4 \cdot 1$ & $8 \cdot 2$ & 1.0 & 24 & 18 & 2.4 & 5.4 \\
\hline & & & & & & 65.0 & $16 \cdot 46$ & $2 \cdot 72$ & $35 \cdot 7$ & 5.8 & $6 \cdot 2$ & $1 \cdot 3$ & 44 & 21 & $3 \cdot 1$ & 4.6 \\
\hline \multirow[t]{2}{*}{ d } & $\mathbf{M}$ & 51 & ++ & C & 4 & 71.0 & 13.00 & $2 \cdot 10$ & $27 \cdot 4$ & $4 \cdot 1$ & $6 \cdot 7$ & 2.0 & 51 & 44 & $2 \cdot 7$ & 5.9 \\
\hline & & & & & & $72 \cdot 5$ & $14 \cdot 58$ & 2.49 & $34 \cdot 6$ & 3.7 & $9 \cdot 3$ & 1.4 & 27 & 40 & 3.6 & 6.0 \\
\hline \multirow[t]{3}{*}{ e } & $\mathbf{F}$ & 23 & +++ & C & 13 & $37 \cdot 3$ & $10 \cdot 60$ & 1.66 & 30.4 & 2.5 & $12 \cdot 2$ & 0.5 & 142 & 60 & $2 \cdot 7$ & $8 \cdot 3$ \\
\hline & & & & & & 41.0 & 10.39 & 1.81 & 44.5 & $2 \cdot 7$ & $16 \cdot 5$ & 一 & 一 & 一 & $3 \cdot 6$ & - \\
\hline & & & & & & 44.6 & 12.36 & 1.96 & 62.5 & $3 \cdot 3$ & 18.9 & 0.5 & 40 & 24 & 2.7 & 4.6 \\
\hline \multirow[t]{2}{*}{ f } & $\mathbf{F}$ & 15 & +++ & C & 16 & 45.9 & 8.63 & 1.35 & 30.9 & $2 \cdot 2$ & $13 \cdot 7$ & 1.7 & 500 & 6 & 2.9 & $7 \cdot 7$ \\
\hline & & & & & & 50.0 & $9 \cdot 68$ & 1.69 & $42 \cdot 3$ & 3.5 & 12.0 & 0.7 & 25 & 8 & $3 \cdot 5$ & $5 \cdot 3$ \\
\hline \multirow[t]{2}{*}{8} & $\mathbf{F}$ & 51 & ++ & C & 2 & $53 \cdot 1$ & $11 \cdot 78$ & 2.03 & 50.0 & $2 \cdot 7$ & 18.5 & 1.5 & 35 & 70 & $2 \cdot 2$ & $7 \cdot 4$ \\
\hline & & & & & & 54.5 & 12.06 & $2 \cdot 11$ & $50 \cdot 2$ & 2.5 & $20 \cdot 1$ & 1.0 & 28 & 75 & 2.5 & 5.0 \\
\hline \multirow[t]{2}{*}{ h } & $\mathbf{F}$ & 57 & + & C & 6 & 51.8 & 13.65 & $2 \cdot 16$ & $12 \cdot 1$ & 7.0 & $1 \cdot 7$ & 0.5 & 35 & 13 & 4.5 & 3.0 \\
\hline & & & & & & 51.8 & 13.05 & $2 \cdot 34$ & 23.8 & 3.7 & $6 \cdot 4$ & $2 \cdot 1$ & 39 & 11 & $5 \cdot 3$ & 3.0 \\
\hline \multirow[t]{2}{*}{ i } & $\mathbf{F}$ & 71 & + & C & 3 & 60.0 & 13.75 & $2 \cdot 37$ & $19 \cdot 7$ & 4.9 & $4 \cdot 0$ & 0.8 & 20 & 15 & 2.5 & $4 \cdot 1$ \\
\hline & & & & & & 61.4 & 13.81 & $2 \cdot 35$ & 33.5 & $4 \cdot 5$ & $7 \cdot 5$ & 1.4 & 25 & 11 & $3 \cdot 2$ & 3.6 \\
\hline \multirow[t]{2}{*}{$\mathbf{j}$} & $\mathbf{F}$ & 28 & ++ & C & 3 & $59 \cdot 1$ & 15.60 & $2 \cdot 50$ & 14.0 & 4.9 & 2.9 & - & - & - & $3 \cdot 7$ & 3.6 \\
\hline & & & & & & $57 \cdot 7$ & $16 \cdot 70$ & 2.65 & $23 \cdot 0$ & 3.5 & $6 \cdot 6$ & 2.4 & 45 & 23 & $4 \cdot 3$ & 2.8 \\
\hline \multirow[t]{4}{*}{ k } & $\mathbf{F}$ & 49 & ++ & - & 7 & $47 \cdot 7$ & $12 \cdot 76$ & $2 \cdot 15$ & $28 \cdot 8$ & $4 \cdot 8$ & 5.9 & 0.5 & 50 & 16 & 3.9 & $3 \cdot 1$ \\
\hline & & & & & & 47.6 & $9 \cdot 81$ & 1.76 & $33 \cdot 6$ & $4 \cdot 8$ & 6.9 & 0.5 & 20 & - & - & 一 \\
\hline & & & & & & 47.5 & 12.49 & 1.97 & 39.8 & $6 \cdot 8$ & 5.8 & 一 & - & - & - & - \\
\hline & & & & & & $45 \cdot 4$ & 12.54 & 2.04 & $54 \cdot 3$ & 5.4 & 10.0 & 0.5 & 11 & 8 & 3.9 & 3.4 \\
\hline \multirow[t]{2}{*}{1} & $\mathbf{M}$ & 17 & ++ & C & 4 & $48 \cdot 1$ & 8.62 & 1.53 & $23 \cdot 7$ & $2 \cdot 3$ & $10 \cdot 3$ & 1.0 & 112 & 10 & 4.5 & $2 \cdot 3$ \\
\hline & & & & & & $48 \cdot 1$ & 9.75 & $1 \cdot 71$ & 25.2 & 2.4 & 10.5 & 0.9 & 35 & 7 & $4 \cdot 3$ & 2.6 \\
\hline \multirow[t]{4}{*}{$\mathrm{m}$} & $\mathbf{M}$ & 21 & + & - & 3 & $54 \cdot 1$ & 12.41 & $2 \cdot 12$ & $48 \cdot 7$ & 3.5 & 13.9 & 1.5 & 110 & 17 & 3.8 & 3.9 \\
\hline & & & & & & $54 \cdot 1$ & $12 \cdot 38$ & 2.07 & $48 \cdot 8$ & $4 \cdot 0$ & $12 \cdot 2$ & - & - & - & - & - \\
\hline & & & & & & $54 \cdot 2$ & 12.96 & $2 \cdot 26$ & 52.6 & $4 \cdot 4$ & 11.9 & - & - & - & - & 一 \\
\hline & & & & & & 54.4 & $12 \cdot 50$ & $2 \cdot 20$ & $74 \cdot 4$ & 5.0 & 14.9 & $1 \cdot 2$ & 13 & 8 & $4 \cdot 4$ & 3.9 \\
\hline \multirow[t]{4}{*}{$\mathrm{n}$} & $\mathbf{F}$ & 16 & ++ & - & 4 & 50.5 & $10 \cdot 46$ & 1.78 & $28 \cdot 6$ & 3.4 & 8.5 & $8 \cdot 4$ & 93 & 26 & - & 一 \\
\hline & & & & & & $50 \cdot 5$ & 10.71 & 1.70 & 35.9 & 1.6 & $22 \cdot 2$ & - & - & - & 4.7 & $5 \cdot 3$ \\
\hline & & & & & & 50.9 & $10 \cdot 54$ & 1.86 & $16 \cdot 1$ & $3 \cdot 4$ & $4 \cdot 7$ & - & - & - & 3.8 & 7.5 \\
\hline & & & & & & 52.0 & $10 \cdot 21$ & 1.76 & 25.0 & 3.0 & $8 \cdot 3$ & 4.7 & 70 & 27 & 3.8 & 4.8 \\
\hline \multirow[t]{2}{*}{ o } & $\mathbf{M}$ & 42 & +++ & C & 20 & $69 \cdot 1$ & $14 \cdot 10$ & $2 \cdot 41$ & $33 \cdot 1$ & $2 \cdot 9$ & 8.8 & 3.7 & 85 & 27 & 3.4 & 5.0 \\
\hline & & & & & & $85 \cdot 5$ & 16.00 & 2.78 & $33 \cdot 2$ & $4 \cdot 8$ & 6.9 & 0.5 & 16 & 19 & 3.7 & $3 \cdot 3$ \\
\hline \multirow[t]{3}{*}{$p$} & $\mathbf{F}$ & 59 & ++ & C & 4 & $70 \cdot 7$ & 12.89 & $2 \cdot 30$ & 5.4 & $4 \cdot 2$ & $1 \cdot 3$ & 4.0 & 66 & 21 & 3.8 & 3.6 \\
\hline & & & & & & $\begin{array}{l}69 \cdot 9 \\
66 \cdot 4\end{array}$ & $\begin{array}{l}14 \cdot 10 \\
13 \cdot 13\end{array}$ & $\begin{array}{l}2.56 \\
2.25\end{array}$ & $\begin{array}{l}15.3 \\
18.7\end{array}$ & $\begin{array}{l}4.5 \\
4.7\end{array}$ & $\begin{array}{l}3.4 \\
4.0\end{array}$ & $\overrightarrow{2.0}$ & $\overrightarrow{20}$ & $\overline{27}$ & $\overline{3.7}$ & $\overline{3.9}$ \\
\hline & & & & & & & & & & & & & & 27 & 3.7 & 3.9 \\
\hline
\end{tabular}

${ }^{1}$ For each patient, the first estimation was done immediately before starting corticosteroids. $\mathrm{C}=$ cirrhosis.

$(\mathrm{r}=-0.501 ; \mathrm{P}<0.01)$ in individual patients in the two groups. The correlation between percentage change in storage (S) and change in serum aspartate transaminase is not significant $(r=-0.267$; $\mathbf{P}<0 \cdot 10$ ). There is not a significant correlation between percentage change in transport maximum (Tm) and change in serum alkaline phosphatase in the two groups $(r=+0 \cdot 110)$.

Urinary BSP during the $S$ and $T m$ determinations was estimated in most patients studied; this was approximately $5 \%$ of the total BSP infused, and in no case greater than $10 \%$. Urinary BSP excretion was not influenced by corticosteroids.
STORAGE (s) AND TRANSPORT MAXIMUM (Tm) IN CHOLESTATIC VIRUS HEPATITIS AND OBSTRUCTIVE JAUNDICE Table VI summarizes the results. Figure 6 shows the changes in serum bilirubin and BSP S and $\mathrm{Tm}$ in a patient with cholestatic virus hepatitis (patient P.B.). After four weeks of jaundice, prednisolone (30 mg daily) was started. Serum bilirubin and aspartate transaminase fell rapidly; storage (S) increased from 16.0 to $33.9 \mathrm{mg} / \mathrm{mg} / 100 \mathrm{ml}$; Tm fell from 4.4 to $2.6 \mathrm{mg} / \mathrm{min}$; and the $\mathrm{S} / \mathrm{Tm}$ ratio increased from 3.6 to 13.0 . The two patients treated with prednisolone had an increase in BSP storage (S) of $112 \%$ and $99 \%$ respectively during the first 
TABLE V

SERIAL ESTIMATIONS OF STORAGE (s) AND TRANSPORT MAXIMUM (Tm) FOR BSP IN A GROUP OF PATIENTS WITH ACTIVE CHRONIC HEPATITIS NOT RECEIVING CORTICOSTEROIDS AND BIOCHEMICAL INDICES

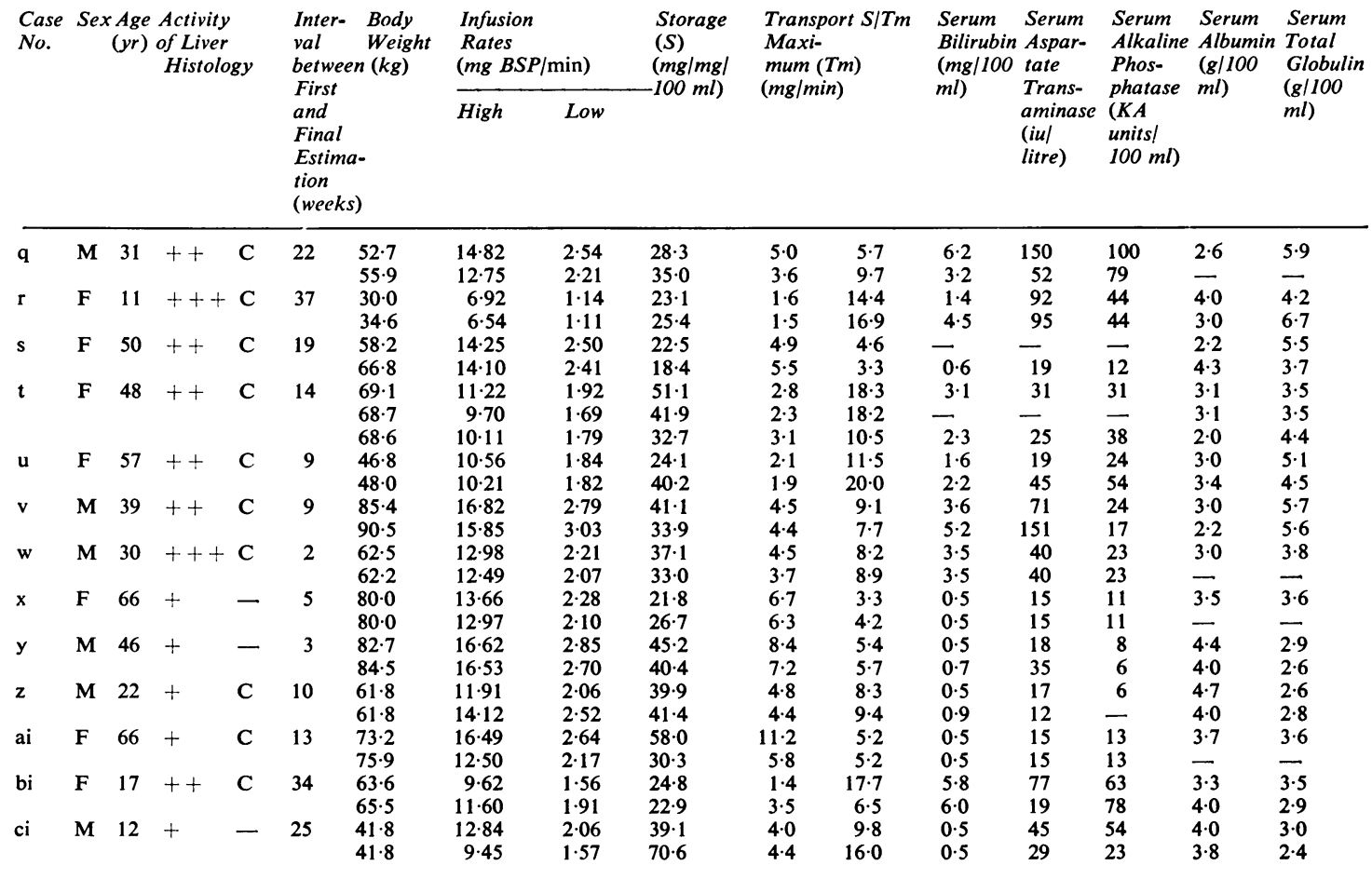

$\mathrm{C}=$ cirrhosis

72 hours; the third patient, who was not given a corticosteroid, had an increase of $14 \%$ during 72 hours and $2 \%$ during the following seven days. In the treated patients, the transport maximum (Tm) decreased by $41 \%$ and $14 \%$ respectively, and in the control it increased by $4 \%$ in 72 hours, and $13 \%$ in the next seven days. Serum bilirubin fell from $24 \cdot 0$ to $13.0 \mathrm{mg} / 100 \mathrm{ml}$ and 2.2 to $1.1 \mathrm{mg} / 100 \mathrm{ml}$ in the treated patients; it was relatively constant in the control. Aspartate transaminase fell from 285 to 115 and 148 to $35 \mathrm{iu} /$ litre in the treated patients, and from 39 to $28 \mathrm{iu} /$ litre in the control. Alkaline phosphatase values showed little change.

Figure 7 shows the changes in serum bilirubin and $S$ and $T m$ in a patient with carcinoma of the head of the pancreas (patient W.H.). Bromsulphthaiein storage (S) was $16.1 \mathrm{mg} / \mathrm{mg} / 100 \mathrm{ml}$ before corticosteroids and $15.5 \mathrm{mg} / \mathrm{mg} / 100 \mathrm{ml}$ five days later; the fall was $4 \%$ of the initial level. Transport maximum at the corresponding times was 2.7 and $2.6 \mathrm{mg} / \mathrm{min}$; an increase of $4 \%$. Storage/transport maximum was 6.0 before and after corticosteroids. Biochemical indices remained essentially constant.
CHROMATOGRAPHIC STUDIES OF BSP IN PATIENTS WITH ACTIVE CHRONIC HEPATITIS Tables VII and VIII summarize the results. The mean interval between the two BSP estimations was five (2-16) and seven (2-14) weeks in the group treated with prednisolone and the control group respectively. High conjugated BSP levels were common in the early samples (Plaa, Sparks, and Hunter, 1962), and were not influenced by corticosteroids. Attention was confined to 30minute specimens (Tables VII and VIII). The level of conjugated BSP at the first estimation was 29.1 (3.4 to 82.6$) \%$ in the treated, and $39.4(7.8$ to 94.9$) \%$ in the control group. The mean difference between the percentage of BSP conjugated at the first and second estimation was $+22.4(-55.0$ to +79.5$) \%$ in the treated, and $-7 \cdot 8(-68 \cdot 2$ to $+57 \cdot 6) \%$ in the control group; the difference between the means is significant $(P<0.02)$ (Fig. 8). All of these patients also had BSP storage (S) and Tm estimations. The correlation between percentage change in storage (S) and change in the level of conjugated BSP in the peripheral blood is not significant $(\mathrm{r}=+0.340 ; \mathrm{P}<0 \cdot 10)$. The correlation between percentage change in transport 
PB.M18.LH.
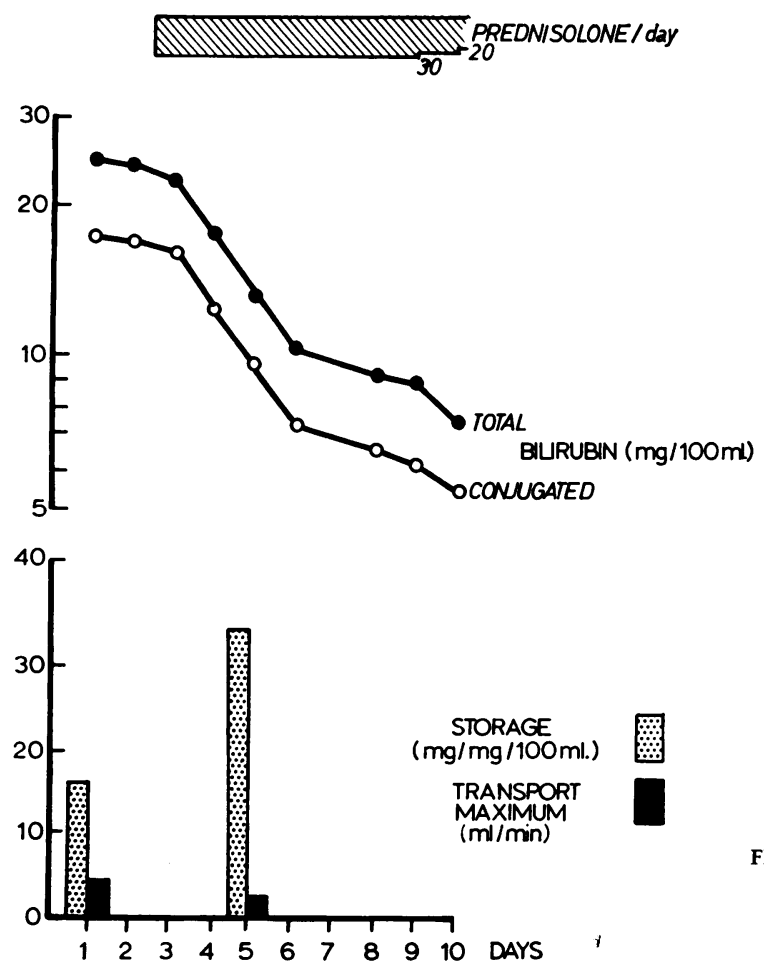

FIG. 6.

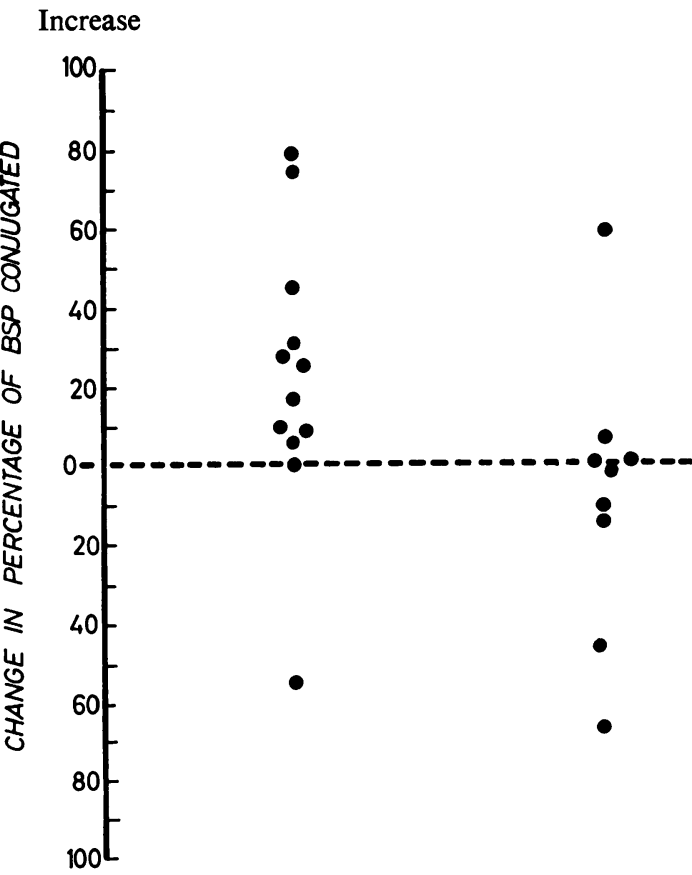

FIG. 8 .

Decrease

Control
Prednisolone $>2$ weeks
FIG. 6. Serum bilirubin and BSP storage $(S)$ and transport maximum $(T m)$ in a patient (P.B.) with cholestatic virus hepatitis before and 72 hours after starting prednisolone.

FIG. 7. Serum bilirubin and BSP storage (S) and transport maximum (Tm) in a patient $(W . H$.$) with extrahepatic$ obstructive jaundice due to pancreatic carcinoma before and five days after starting prednisolone.

FIG. 8. Change in the percentage of BSP conjugated at 30 minutes after an intravenous injection of $5.0 \mathrm{mg}$ per $\mathrm{kg}$ body weight in 'prednisolone' and 'control' groups of patients with active chronic hepatitis between two estimations. The difference between the two means is significant $(P<0.02)$.

FIG. 7. 
TABLE VI

STORAGE (s) AND TRANSPORT MAXIMUM (Tm) FOR BSP IN PATIENTS WITH CHOLESTATIC VIRUS HEPATITIS AND OBSTRUCTIVE JAUNDICE AND BIOCHEMICAL INDICES

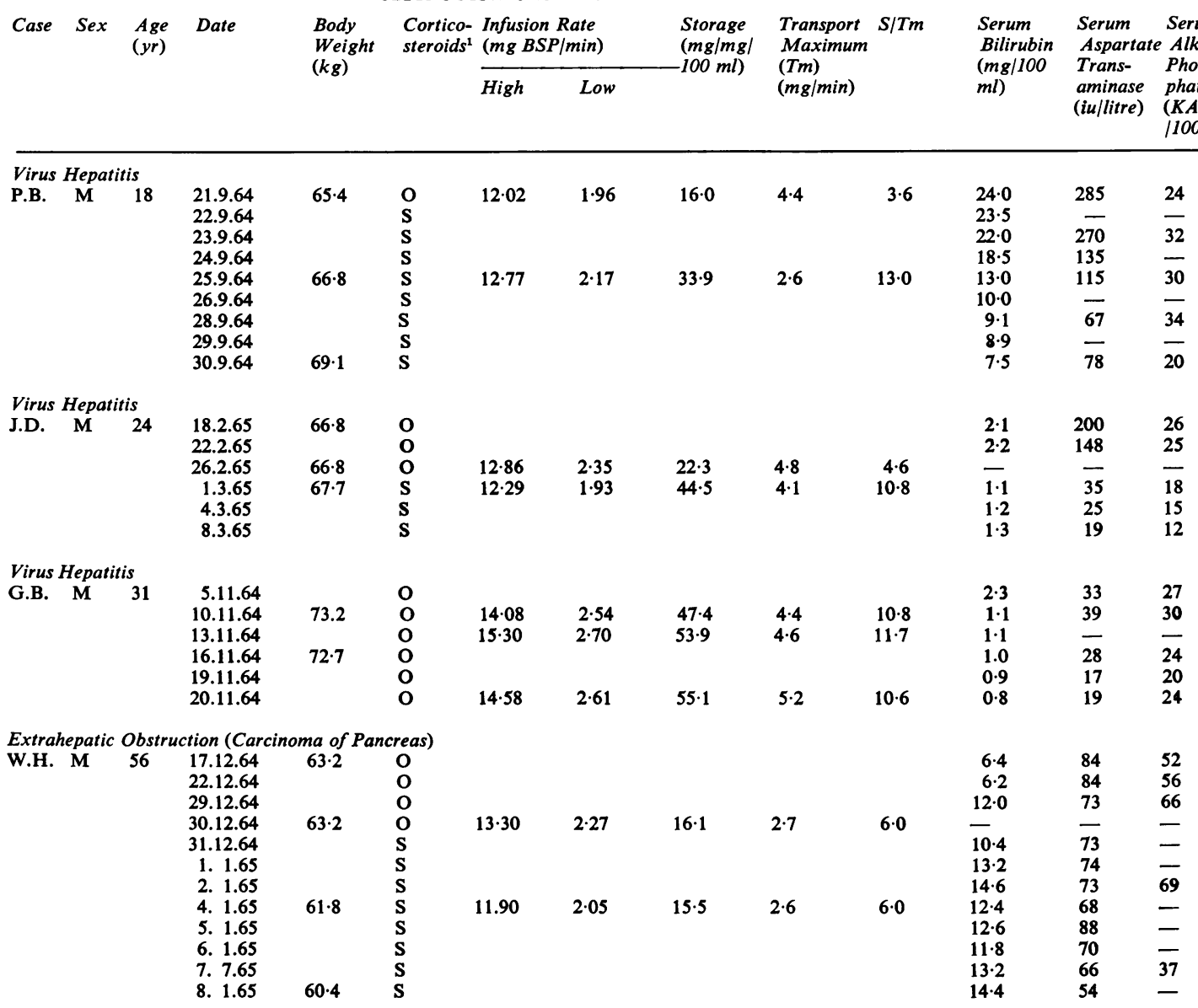

${ }^{1} \mathrm{~S}=$ oral corticosteroids (Prednisolone $30 \mathrm{mg}$ daily)

TABLE VII

CONJUGATION OF BROMSULPHTHALEIN (BSP) IN VENOUS BLOOD AT 30 MINUTES AFTER INTRAVENOUS INJECTION OF $5.0 \mathrm{mg}$ BSP PER $\mathrm{kg}$ BODY WEIGHT IN ACTIVE CHRONIC HEPATITIS TREATED WITH CORTICOSTEROIDS

\begin{tabular}{|c|c|c|c|c|c|c|c|c|c|}
\hline \multirow[b]{2}{*}{ Case No. } & \multirow[b]{2}{*}{$\begin{array}{l}\text { Interval } \\
\text { between } \\
\text { Two Esti- } \\
\text { mations } \\
\text { (weeks) }\end{array}$} & \multicolumn{4}{|c|}{ Before Prednisolone } & \multicolumn{4}{|c|}{ After Oral Prednisolone (15 mg daily) } \\
\hline & & $\begin{array}{l}\% \text { BSP } \\
\text { Retention } \\
\text { at } 30 \\
\text { Minutes }\end{array}$ & $\begin{array}{l}\text { Total BSP } \\
\text { at } 30 \\
\text { Minutes } \\
(\mathrm{mg} / 100 \mathrm{ml})\end{array}$ & $\begin{array}{l}\text { Conjugated } \\
\text { BSP at } 30 \\
\text { Minutes } \\
(\mathrm{mg} / 100 \mathrm{ml})\end{array}$ & $\begin{array}{l}\% \text { BSP } \\
\text { Conjugated } \\
\text { at } 30 \\
\text { Minutes }\end{array}$ & $\begin{array}{l}\% \text { BSP } \\
\text { Retention } \\
\text { at } 30 \\
\text { Minutes }\end{array}$ & $\begin{array}{l}\text { Total BSP } \\
\text { at } 30 \\
\text { Minutes } \\
(\mathrm{mg} / 100 \mathrm{ml})\end{array}$ & $\begin{array}{l}\text { Conjugated } \\
\text { BSP at } 30 \\
\text { Minutes } \\
(\mathrm{mg} / 100 \mathrm{ml})\end{array}$ & $\begin{array}{l}\% \text { BSP } \\
\text { Conjugated } \\
\text { at } 30 \\
\text { Minutes }\end{array}$ \\
\hline i & 7 & $44 \cdot 4$ & $3 \cdot 30$ & 0.19 & $5 \cdot 7$ & 46.8 & 3.40 & 1.09 & $32 \cdot 0$ \\
\hline ii & 4 & $41 \cdot 7$ & 3.40 & $0 \cdot 16$ & $5 \cdot 2$ & $22 \cdot 0$ & 1.80 & 0.58 & $32 \cdot 2$ \\
\hline iii & 8 & $20 \cdot 8$ & 1.46 & 0.40 & $27 \cdot 4$ & $16 \cdot 3$ & $1 \cdot 14$ & 0.83 & 72.8 \\
\hline iv & 16 & $30 \cdot 1$ & $2 \cdot 26$ & 0.29 & $13 \cdot 2$ & $19 \cdot 7$ & 1.40 & 1.25 & $89 \cdot 2$ \\
\hline $\mathbf{v}$ & 2 & $22 \cdot 3$ & 1.45 & 1.00 & 68.9 & 22.6 & 1.58 & 0.22 & 13.9 \\
\hline vi & 3 & $37 \cdot 4$ & 3.50 & 0.12 & 3.4 & $42 \cdot 7$ & 3.60 & 0.46 & 12.8 \\
\hline vii & 6 & $25 \cdot 4$ & 2.80 & 0.11 & 3.9 & $34 \cdot 7$ & $3 \cdot 30$ & 0.30 & 10.9 \\
\hline viii & 2 & 48.7 & 5.08 & $3 \cdot 30$ & 64.9 & $43 \cdot 1$ & 4.57 & 3.70 & 80.9 \\
\hline ix & 2 & $17 \cdot 6$ & $1 \cdot 27$ & 0.07 & $5 \cdot 5$ & 10.0 & 0.80 & 0.68 & 85.0 \\
\hline$x$ & 3 & $36 \cdot 1$ & 3.01 & 1.80 & $60 \cdot 0$ & $19 \cdot 3$ & 200 & 1.80 & 90.0 \\
\hline$x i$ & 2 & $22 \cdot 0$ & $2 \cdot 13$ & 1.76 & 82.6 & 10.9 & $1 \cdot 14$ & 1.02 & 89.5 \\
\hline xii & 3 & 45.0 & $4 \cdot 10$ & 0.36 & $8 \cdot 8$ & 43.0 & 3.90 & 0.35 & 8.9 \\
\hline
\end{tabular}


TABLE VIII

CONJUGATION OF BROMSULPHTHALEIN (BSP) IN VENOUS BLOOD AT 30 MINUTES AFTER INTRAVENOUS INJECTION OF $5.0 \mathrm{mg}$ BSP PER $\mathrm{kg}$ BODY WEIGHT IN ACTIVE CHRONIC HEPATITIS NOT TREATED WITH CORTICOSTEROIDS

\begin{tabular}{|c|c|c|c|c|c|c|c|c|c|}
\hline \multirow[b]{2}{*}{ Case No. } & \multirow[b]{2}{*}{$\begin{array}{l}\text { Interval } \\
\text { between } \\
\text { Two Esti- } \\
\text { mations } \\
\text { (weeks) }\end{array}$} & \multicolumn{4}{|c|}{ Initial Estimation } & \multicolumn{4}{|c|}{ Second Estimation } \\
\hline & & $\begin{array}{l}\% \text { BSP } \\
\text { Retention } \\
\text { at } 30 \\
\text { Minutes }\end{array}$ & $\begin{array}{l}\text { Total BSP } \\
\text { at } 30 \\
\text { Minutes } \\
(\mathrm{mg} / 100 \\
\mathrm{ml})\end{array}$ & $\begin{array}{l}\text { Conjugated } \\
\text { BSP at } 30 \\
\text { Minutes } \\
(\mathrm{mg} / 100 \\
\mathrm{ml})\end{array}$ & $\begin{array}{l}\% \text { BSP } \\
\text { Conjugated } \\
\text { at } 30 \\
\text { Minutes }\end{array}$ & $\begin{array}{l}\% \text { BSP } \\
\text { Retention } \\
\text { at } 30 \\
\text { Minutes }\end{array}$ & $\begin{array}{l}\text { Total BSP } \\
\text { at } 30 \\
\text { Minutes } \\
(\mathrm{mg} / 100 \\
\mathrm{ml})\end{array}$ & $\begin{array}{l}\text { Conjugated } \\
\text { BSP at } 30 \\
\text { Minutes } \\
(\mathrm{mg} / 100 \\
\mathrm{ml})\end{array}$ & $\begin{array}{l}\% \text { BSP } \\
\text { Conjugatcd } \\
\text { at } 30 \\
\text { Minutes }\end{array}$ \\
\hline xiii & 12 & $55 \cdot 1$ & $3 \cdot 43$ & 0.62 & $18 \cdot 2$ & $42 \cdot 7$ & $2 \cdot 98$ & $2 \cdot 26$ & $75 \cdot 8$ \\
\hline xiv & 14 & $48 \cdot 3$ & 4.93 & 0.80 & $16 \cdot 2$ & $29 \cdot 4$ & $3 \cdot 70$ & $0 \cdot 22$ & $5 \cdot 9$ \\
\hline$x v$ & 9 & $47 \cdot 4$ & $3 \cdot 13$ & $1 \cdot 15$ & 36.7 & $52 \cdot 8$ & $3 \cdot 70$ & 1.40 & $37 \cdot 8$ \\
\hline xvi & 8 & $33 \cdot 5$ & 2.78 & 2.64 & 94.9 & $34 \cdot 6$ & $2 \cdot 70$ & 0.72 & $26 \cdot 7$ \\
\hline xvii & 8 & 58.9 & $3 \cdot 24$ & $2 \cdot 20$ & 67.9 & $56 \cdot 5$ & $4 \cdot 46$ & 0.65 & $14 \cdot 6$ \\
\hline xviii & 2 & $42 \cdot 0$ & $3 \cdot 15$ & 0.58 & $18 \cdot 4$ & $44 \cdot 9$ & 3.46 & 0.07 & $2 \cdot 0$ \\
\hline xix & 5 & $16 \cdot 2$ & 1.91 & $0 \cdot 15$ & $7 \cdot 8$ & $18 \cdot 1$ & $2 \cdot 25$ & $0 \cdot 18$ & $8 \cdot 0$ \\
\hline $\mathbf{x x}$ & 3 & $5 \cdot 2$ & 0.63 & $0 \cdot 10$ & 15.9 & $5 \cdot 4$ & 0.63 & $0 \cdot 10$ & 15.9 \\
\hline $\mathrm{xxi}$ & 7 & 10.4 & $0 \cdot 70$ & 0.55 & 78.6 & 10.6 & 0.89 & 0.78 & $87 \cdot 6$ \\
\hline
\end{tabular}

maximum ( $\mathrm{Tm}$ ) and change in the level of conjugated BSP is also not significant $(\mathrm{r}=+0 \cdot 302 ; \mathrm{P}<0 \cdot 10)$. Plasma from six healthy volunteers and six patients with active chronic hepatitis were incubated with BSP in vitro and treated in an identical way to the samples in the study. In no case was an appreciable amount of BSP conjugated. In most patients, chromatography of urinary BSP was performed, and in all most was conjugated.

\section{DISCUSSION}

Intravenously injected bromsulphthalein is excreted mainly by the liver (Rosenthal and White, 1925) although a part may be played by extrahepatic uptake (Cohn, Levine, and Kolinsky, 1948; Rosenau, Carbone, and Grodsky, 1959), and by an enterohepatic circulation (Lorber, Oppenheimer, Shay, Lynch, and Siplet, 1953). With moderate BSP loads as used in the present study, however, insignificant exchange occurs outside the liver (Leevy, 1961; Norberg, Senning, and William-Olsson, 1962) and the studies reported here give precise information on hepatic cellular function.

Increased BSP retention has been shown in the patients with active chronic hepatitis; this agrees with other observers (MacKay et al., 1959; Page and Good, 1960; Reynolds, Edmondson, Peters, and Redeker, 1964). In patients in the controlled trial a significant decrease in BSP retention has been shown during the first few weeks after starting corticosteroids, and this confirms previous uncontrolled observations (Page and Good, 1960; Kern, Vinnik, Struthers, and Hill, 1963). Plasma disappearance rate (PDR) or fractional clearance (MacDonald, 1939; Ingelfinger, Bradley, Mendeloff, and Kramer, 1948; Richards, Tindall, and Young, 1959; Leevy, 1961), which may be abnormal in the presence of a normal 30-minute retention (MacDonald, 1939; Richards et al., 1959), also improved more often in patients treated with corticosteroids; this difference is not, however, significant. The calculated plasma BSP level at zero time and therefore the volume of distribution of BSP relative to body weight varied considerably in the individual patients in this study. Although corticosteroids expand plasma volume and cause fluid retention (Bongiovanni and Eisenmenger, 1951), they have not significantly influenced the volume of distribution of BSP in this study.

The correlation between change in BSP retention and change in serum bilirubin, aspartate transaminase, and total globulin in both groups was significant. Decreased retention seems therefore to reflect a general improvement in hepato-cellular function. This preliminary study of patients in the controlled trial has therefore shown a significant improvement in liver cell function soon after starting corticosteroids.

In order to investigate further the mechanism of the decrease in BSP retention following corticosteroids, BSP transport maximum (Tm) and storage (S) were estimated in a further group of patients with active chronic hepatitis. Impairment of storage (S) and transport maximum (Tm) in patients with untreated active chronic hepatitis (Preisig, Williams, Sweeting, and Bradley, 1963) has been confirmed. Although there was no significant difference between these indices in a group of patients receiving corticosteroids compared with a control group, the following study showed a significant increase in $S$ in patients with active chronic hepatitis after starting corticosteroids. Improvement in $\mathrm{S}$ has therefore been shown to account for at least part of the decrease in BSP retention after corticosteroids. This improvement correlates significantly with a decrease in serum 
bilirubin and total globulin. Storage (S) is a more labile factor than $\mathrm{Tm}$, for in extrahepatic portal obstruction (Thompson, Williams, and Sherlock, 1964) and old age (Thompson and Williams, 1965) it shows a disproportionate reduction. In old age, diminution in storage is paralleled by a diminution in liver size (Thompson and Williams, 1965). It is therefore of interest that corticosteroids can increase liver size (Gyorgy and Bluemle, 1951; Chapman, Kark, Keeton, Calloway, Consolazio, Weigend, Dyniewicz, and Kyle, 1952; Clark, 1953), and this might account for at least part of the increase in $\mathbf{S}$. In animals some therapeutic agents increase BSP uptake by the liver (Fujimoto, Eich, and Nichols, 1965); their effects on storage and transport maximum have not, however, been investigated. In patients with active chronic hepatitis the depressed transport maximum $(\mathrm{Tm})$ improved much less than $\mathrm{S}$. The Tm for BSP is probably constant, and analogous to renal tubular transport (Bradley, Ingelfinger, Bradley, and Curry, 1945; Mason, Hawley, and Smith, 1948; Lewis, 1950; Verschure, 1952; Taleisnik, 1955; Wheeler et al., 1960; Schoenfield et al., 1964). Whether or not there are separate Tm rates for free and conjugated BSP has not yet been determined (Schoenfield, 1965). There was not a significant correlation in the present study between change in $\mathrm{Tm}$ and change in serum alkaline phosphatase.

In two patients with cholestatic virus hepatitis, corticosteroids resulted in a very rapid increase in BSP storage (S). This paralleled closely the fall in serum bilirubin and aspartate transaminase and probably reflects an acceleration of the improvement in hepatic function which occurs during natural recovery. One of the patients studied showed a striking increase in BSP storage (S) although the initial serum bilirubin was only $2 \cdot 2 \mathrm{mg} / 100 \mathrm{ml}$. The change is not therefore a result of the fall in the serum bilirubin level. Improvement in $\mathbf{S}$ during recovery occurs before that in Tm (Schoenfield et al., 1964; Preisig et al., 1966).

Suggested mechanisms for the fall in bilirubin after corticosteroids are increased choleresis (Patterson, Dingman, Shwachman, and Thorn, 1954), increased urinary excretion, and decreased red cell destruction. All of these, however, seem unlikely (Williams and Billing, 1961). A direct effect of corticosteroids on the liver (Katz, Ducci, and Alessandri, 1957; Summerskill, Clowdus, Bollman, and Fleisher, 1961), or an altered or additional metabolic pathway (Chalmers, Gill, Jernigan, Svec, Jordan, Waldstein, and Knowlton, 1956; Williams and Billing, 1961) have also been suggested as an explanation. In the present study, the patient with complete extrahepatic biliary obstruction showed very little change in BSP storage (S) or the serum bilirubin level. Although hepatic storage for bilirubin has not been demonstrated, this must presumably exist. The present study suggests that in cholestatic virus hepatitis corticosteroids increase bilirubin storage in parenchymal cells; this would account for the rapid fall in serum bilirubin during the first 48-72 hours of treatment (Williams and Billing, 1961). In all cases in the present study, Tm showed much less variation than $\mathrm{S}$; excretion of bilirubin has also been shown to be by a rate-limited process with a fixed Tm (Weinbren and Billing, 1956; Arias, Johnson, and Wolfson, 1961; Brown, Grodsky, and Carbone, 1964). Conjugation of bilirubin is also probably increased by corticosteroids (O'Donnell, Mistilis, Schiff, and Cobb, 1963). The cause of the sudden fall in serum aspartate transaminase after corticosteroids is not adequately explained (O'Brien, Goble, and MacKay, 1958; Redeker, Reynolds, and Kuzma, 1961); it is certainly not due to an abrupt cessation of hepatocellular destruction as this continues microscopically throughout the course of the disease. This may also be due, in part at least, to a general increase in hepatic storage.

Conjugation of BSP is largely with glutathione and takes place mainly in the liver (Brauer, Pessotti, and Krebs, 1955; Combes, 1959; Grodsky et al., 1959; Meltzer, Wheeler, and Cranston, 1959; Javitt et al., 1959). In the present study, the 30-minute level of conjugated BSP increased significantly more in the patients who received corticosteroids than in the controls. In infective hepatitis and cirrhosis, low levels of conjugate are present (Carbone, Grodsky, and Hjelte, 1959; Plaa, et al., 1962; Schoenfield et al., 1964); but the level rises in infective hepatitis during recovery (Plaa et al., 1962). The increase in conjugated BSP after corticosteroids is probably also due to parenchymal cell recovery, and it may reflect an adaptive improvement in enzyme action (Burns, Conney, and Koster, 1963) analogous to that following therapeutic agents (Fujimoto et al., 1965). Conjugation is probably important in the biliary excretion of BSP (Philp, Grodsky, and Carbone, 1961) but the present study suggests that it is not essential; there was not a significant correlation between change in storage (S) and conjugation, or between change in $\mathrm{Tm}$ and conjugation. As expected, most urinary BSP in the present study was conjugated (Carbone et al., 1959).

\section{SUMMARY}

Serial intravenous bromsulphthalein (BSP) disappearance curves have been performed in two randomly selected groups of patients with active chronic hepatitis who had not previously received 
corticosteroids. Bromsulphthalein retention decreased significantly more in the group treated with corticosteroids than in the control group.

Decrease in BSP retention has been shown to correlate well with improvement in other biochemical indices of hepatocellular function, and was not dependent on initial serum bilirubin levels.

Relative hepatic storage (S) for BSP increased more in a group of patients with active chronic hepatitis after starting treatment with corticosteroids than in a control group who were not so treated. In both groups, the transport maximum (Tm) for BSP remained relatively constant.

Similar results for $\mathbf{S}$ and $\mathrm{Tm}$ were seen in two patients with cholestatic virus hepatitis who were treated with corticosteroids. A patient with complete biliary obstruction due to carcinoma of the pancreas showed no significant change in $\mathrm{S}$ or $\mathrm{Tm}$ after corticosteroids.

Patients with active chronic hepatitis given intravenous BSP showed a significant increase in plasma conjugated BSP after corticosteroids.'

We thank Dr Norman Javitt for advice regarding the chromatography of bromsulphthalein, Professor D. N. Baron for biochemical estimations, and Dr P. J. Scheuer for help with the histological interpretations.

One of us (G.C.C.) acknowledges with thanks financial assistance provided by the William Shepherd bequest to the Royal Free Hospital. This investigation formed part of a thesis submitted in 1965 by G.C.C. to the University of London for the degree of Doctor of Medicine.

\section{REFERENCES}

Adams, R. H., Gordon, J., and Combes, B. (1966). Measurements of hepatic storage and of maximal biliary transport of sulfobromophthalein sodium in man. Gastroenterology, 51, 373-376.

Arias, I. M., Johnson, L., and Wolfson, S. (1961). Biliary excretion of injected conjugated and unconjugated bilirubin by normal and Gunn rats. Amer. J. Physiol., 200, 1091-1094.

Bartholomew, L. G., Hagedorn, A. B., Cain, J. C., and Baggenstoss, A. H. (1958). Hepatitis and cirrhosis in women with positive clot tests for lupus erythematosus. New Engl. J. Med., 259, 947-956.

—, Cain, J. C., Baggenstoss, A. H., and Hagedorn, A. B. (1960). Further observations on hepatitis and cirrhosis in young women with positive clot tests for lupus erythematosus. Gastroenterology, 39, 730-736.

Bearn, A. G., Kunkel, H. G., and Slater, R. J. (1956). The problem of chronic liver disease in young women. Amer. J. Med., 21, 3-15.

Bell, J. L., and Collier, M. (1964). A shortened automated procedure for the determination of alkaline phosphatase. J. clin. Path., 17, 301-303.

Bongiovanni, A. M., and Eisenmenger, W. J. (1951). Adrenal cortical metabolism in chronic liver disease. J. clin. Endocr., 11, 152-172.

Bradley, S. E., Ingelfinger, F. J., Bradley, G. P., and Curry, J. J. (1945.) The estimation of hepatic blood flow in man. J. clin. Invest., 24, 890-897.

Brauer, R. W., Pessotti, R. L., and Krebs, J. S. (1955). The distribution and excretion of S35-labeled sulfo-bromophthalein-sodium administered to dogs by continuous infusion. Ibid., 34, 35-43.

Brown, W. R., Grodsky, G. M., and Carbone, J. V. (1964). Intracellular distribution of tritiated bilirubin during hepatic uptake and excretion. Amer. J. Physiol., 207, 1237-1241.

Burns, J. J., Conney, A. H., and Koster, R. (1963). Stimulatory effect of chronic drug administration on drug-metabolizing enzymes in liver microsomes. Ann. N.Y. Acad. Sci., 104, $881-893$.

Carbone, J. V., Grodsky, G. M., and Hjelte, V. (1959). Effect of hepatic dysfunction on circulating levels of sulfobromophthalein and its metabolites. J. clin. Invest., 38, 1989-1995.

Chalmers, T. C., Gill, R. J., Jernigan, T. P., Svec, F. A., Jordan, R. S., Waldstein, S. S., and Knowlton, M. (1956). Evaluation of a four-day ACTH test in the differential diagnosis of jaundice. Gastroenterology, 30, 894-899.

Chapman, R. A., Kark, R. M., Keeton, R. W., Calloway, N. O., Consolazio, C. F., Weigend, G. E., Dyniewicz, J. M., and Kyle, R. H. (1952). Observations on Laennec's cirrhosis: the effects of cortisone acetate during low-sodium regimen. J. Lab. clin. Med., 40, 744-754.

Clark, I. (1953). The effect of cortisone upon protein synthesis. J. biol. Chem., 200, 69-76.

Cohn, C., Levine, R., and Kolinsky, M. (1948). Hepatic and peripheral removal rates, in the dog, for intravenously injected bromsulphthalein. Amer. J. Physiol., 155, 286-289.

Combes, B. (1959). The biliary excretion of sulfobromophthalein sodium (BSP) in the rat as a conjugate of glycine and glutamic acid. J. clin. Invest., 38, 1426-1433.

Fujimoto, J. M., Eich, W. F., and Nichols, H. R. (1965). Enhanced sulfobromophthalein disappearance in mice pretreated with various drugs. Biochem. Pharmacol., 14, 515-524.

Grodsky, G. M., Carbone, J. V., and Fanska, R. (1959). Identification of metabolites of sulfobromophthalein, J. clin. Invest. 38, 1981-1988.

Gyorgy, P., and Bluemle, L. W., Jr. (1951). The treatment of chronic inflammatory liver disease with ACTH and cortisone. Proc. 2nd Clinical ACTH Conference, Vol. 1, p. 386, edited by J. R. Mote. Churchill, London.

Ingelfinger, F. J., Bradley, S. E., Mendeloff, A. I., and Kramer, P. (1948). Studies with bromsulphthalein. I. Its disappearance from the blood after a single intravenous injection. Gastroenter ology, 11, 646-657.

Javitt, N. B., Wheeler, H. O., Baker, K. J., and Ramos, O. (1959). Intrahepatic conjugation of bromsulphthalein and glutathione. (Abstract.) J. clin. Invest., 38, 1015.

,,,---- , and Bradley, S. E. (1960). The intrahepatic conjugation of sulfobromophthalein and glutathione in the dog. Ibid., 39, 1570-1577.

Jones, W. A., and Castleman, B. (1962). Liver disease in young women with hyperglobulinemia. Amer. J. Path., 40, 315-329.

Katz, R., Ducci, H., and Alessandri, H. (1957). Influence of cortisone and prednisolone on hyperbilirubinemia. J. clin. Invest., 36, 1307-1374.

Kern, F., Jr, Vinnik, I. E., Struthers, J. E., Jr, and Hill, R. B. (1963). The treatment of chronic hepatitis with adrenal cortical hormones. Amer. J. Med., 35, 310-322.

Leevy, C. M. (1961). Dye extraction by the liver. Progr. Liver Dis., 1, 174-186.

Lewis, A. E. (1950). Investigation of hepatic function by clearance techniques. Amer. J. Physiol., 163, 54-61.

Lorber, S. H., Oppenheimer, M. J., Shay, H., Lynch, P., and Siplet, H. (1953). Enterohepatic circulation of bromsulphthalein: intraduodenal, intraportal and intravenous dye administration in dogs. Ibid., 173, 259-264.

MacDonald, D. (1939). A practical and clinical test for liver reserve. Surg. Gynec. Obstet., 69, 70-82.

Mackay, I. R., Taft, L. I., and Cowling, D. C. (1956). Lupoid hepatitis. Lancet, 2, 1323-1326.

,,,$---(1959)$. Lupoid hepatitis and the hepatic lesions of systemic lupus erythematosus. Ibid., 1, 65-69.

MacLachlan, M. J., Rodnan, G. P., Cooper, W. M., and Fennell, R. H., Jr (1965). Chronic active ('lupoid') hepatitis: a clinical, serological, and pathological study of 20 patients. Ann. intern. Med., 62, 425-462.

Mason, M. F., Hawley, G., and Smith, A. (1948). Application of the saturation principle to the estimation of functional hepatic mass in normal dogs. Amer. J. Physiol., 152, 42-47.

Meltzer, J. I., Wheeler, H. O. and Cranston, W. I. (1959). Metabolism of sulfobromophthalein sodium (BSP) in dog and man. Proc. Soc. exp. Biol. ( $N$ Y.), 100, 174-179.

Michaëlsson, M. (1961). Bilirubin determination in serum and urine. Scand. J. clin. Lab. Invest., suppl. 56.

Norberg, B., Senning, $\AA$., and William-Olsson, G. (1962). On the reversible extraction of bromsulfalein (BSP) in the liver. Acta physiol. scand., 55, 26-34. 
O'Brien, F. N., Goble, A. J., and MacKay, I. R. (1958). Plasmatransaminase activity as an index of the effectiveness of cortisone in chronic hepatitis. Lancet, 1, 1245-1249.

O'Donnell, J. F., Mistilis, S. P., Schiff, L., and Cobb, T. (1963). The effect of steroids on bilirubin clearance in the isolated perfused rat liver and in the intact rat. (Abstract.) Gastroenterology, 44, 476.

Page, A. R., and Good, R. A. (1960). Plasma-cell hepatitis, with special attention to steroid therapy. Amer. J. Dis. Child., 99, 288-314.

Patterson, P. R., Dingman, J. F., Shwachman, H., and Thorn, G. W. (1954). Choleretic action of cortisone. New Engl. J. Med., 251, 502-508.

Philp, J., Grodsky, G. M., and Carbone, J. V. (1961). Mercaptide conjugation in the uptake and secretion of sulfobromophthalein. Amer. J. Physiol., 200, 545-547.

Plaa, G. L., Sparks, R. D., and Hunter, F. M. (1962). A study on the appearance of altered sulfobromophthalein (BSP) in human serum. Gastroenterology, 42, 678-683.

Preisig, R., Williams, R., Sweeting, J., and Bradley, S. E. (1963). Quantitative approach to the study of liver function in normal man, during the course of hepatitis and in other forms of liver disease. (Abstract.) Ibid., 44, 479.

$-,-\ldots,-$ - (1966). Changes in sulfobromophthalein transport and storage by the liver during viral hepatitis in man. Amer. J. Med., 40, 170-183.

Read, A. E., Sherlock, S., and Harrison, C. V. (1963). Active 'juvenile' cirrhosis considered as part of a systemic disease and the effect of corticosteroid therapy. Gut, 4, 378-393.

Redeker, A. G., Reynolds, T. B., and Kuzma, O. T. (1961). The effect of cortisone on SGOT and SGPT levels in acute viral hepatitis. (Abstract.) Gastroenterology, 40, 560-561.

Reitman, S., and Frankel, S. (1957). A colorimetric method for the determination of serum glutamic oxalacetic and glutamic pyruvic transaminases. Amer. J. clin. Path., 28, 56-63.

Reynolds, T. B., Edmondson, H. A., Peters, R. L., and Redeker, A. (1964). Lupoid hepatitis. Ann. intern. Med. 61, 650-666.

Richards, T. G., Tindall, V. R., and Young, A. (1959). A modification of the bromsulphthalein liver function test to predict the dye content of the liver and bile. Clin. Sci., 18, 499-511.

Rosenau, W., Carbone, J. V., and Grodsky, G. M. (1959). Metabolism of sulfobromophthalein in hepatectomized and hepatectomizednephrectomized dog. Proc. Soc. exp. Biol. (N.Y.), 102, 131-133.

Rosenthal, S. M. and White, E.C. (1925). Clinical application of the bromsulphthalein test for hepatic function. J. Amer. med. Ass., 84, 1112-1114.

Saint, E. G., King, W. E., Joske, R. A., and Finckh, E. S. (1953). The course of infectious hepatitis with special reference to prognosis and the chronic stage. Aust. Ann. Med., 2, 113-127.

Schoenfield, L. J. (1965). Sulfobromophthalein transport and metabolism. Gastroenterology, 48, 530-533.

-, McGill, D. B., and Foulk, W. T. (1964). Studies of sulfobromophthalein sodium (BSP) metabolism in man. III. Demonstration of transport maximum (Tm) for biliary excretion of BSP. J. clin. Invest., 43, 1424-1432.

Seligson, D., Marino, J., and Dodson, E. (1957). Determination of sulfobromophthalein in serum. Clin. Chem., 3, 638-645.

Summerskill, W. H. J., Clowdus, B. F., II, Bollman, J. L., and Fleisher, G. A. (1961). Clinical and experimental studies on the effect of corticotropin and steroid drugs on bilirubinemia. Amer. $J$. med. Sci., 241, 555-562.

Taleisnik, S. (1955). Liver mass determination of bromsulphthalein in partially hepatectomized rabbits. Gastroenterology, 29, 64-70.

Thompson, E. N., Williams, R., and Sherlock, S. (1964). Liver function in extrahepatic portal hypertension. Lancet, 2, 1352-1356.

reference to bromsulphthalein excretion. Gut, 6, 266-269.

Verschure, J. C. M. (1952). Clinical use of measurements of clearance and maximum capacity of the liver. Acta med. scand., 142, 409-419.

Weinbren, K., and Billing, B. H. (1956). Hepatic clearance of bilirubin as an index of cellular function in the regenerating rat liver. Brit. J. Path., 37, 199-204.

Wheeler, H. O., Meltzer, J. I., and Bradley, S. E. (1960). Biliary transport and hepatic storage of sulfobromophthalein sodium in the unanaesthetized dog, in normal man, and in patients with hepatic disease. J. clin. Invest., 39, 1131-1144.

Williams, R. (1965). The assessment of liver function. Anaesthesia, 20, 3-18.

_- Billing, B. H. (1961). Action of steroid therapy in jaundice. Lancet, 2, 392-396.

Wolfson, W. Q., Cohn, C., Calvary, E., and Ichiba, F. (1948). Studies in serum proteins. V. A rapid procedure for the estimation of total protein, true albumin, total globulin, alpha globulin, beta globulin and gamma globulin in $1.0 \mathrm{ml}$ of serum. Amer. J. clin. Path., 18, 723-730. 